\section{Malabsorption Is Uncommon in Restless Legs Syndrome}

Celiac disease (CD), which is one of the most important malabsorptive diseases in adults, has been associated with several neurological disorders including peripheral neuropathy, cerebellar ataxia, myopathy, and attention deficit hyperactivity disorders. Recently, 2 independent studies ${ }^{1,2}$ reported a high prevalence of restless legs syndrome (RLS) in $\mathrm{CD}$ patients $(25 \%-31 \%)$. In the first study, ${ }^{1}$ iron deficiency was present in $40 \%$ of CD patients with active RLS compared with $6 \%$ of patients without RLS, whereas in the second study, ${ }^{2}$ no significant correlation was found between RLS and iron parameters. Other authors ${ }^{3}$ reported 4 patients with RLS and serum ferritin below $25 \mathrm{ng} / \mathrm{mL}$ whose screening tests were positive for CD. Because these data suggest that CD is frequently associated with RLS and because CD could be an underlying correctable factor for some patients diagnosed with idiopathic RLS, we evaluated the absorptive status in 112 consecutive patients referred to our Sleep Disorders Center (68 women, 44 men; mean age, 59.6 years) with a diagnosis of idiopathic RLS. The diagnosis of RLS was made by face-to-face interview using International Restless Legs Syndrome Study Group (IRLSSG) criteria. ${ }^{4}$ In our patients, mean RLS severity according to the IRLSSG rating scale ${ }^{5}$ was 24.9 (range, 10-38). Using current criteria, ${ }^{6}$ $\mathrm{CD}$ diagnosis was based on the presence of specific screening antibodies in serum (antitransglutaminase IgAtTG) and on the evidence of intestinal damage at duodenal biopsy.

For investigating malabsorption in our RLS patients, the following typical symptoms and signs of $\mathrm{CD}^{7}$ were considered: abdominal pain, anorexia, diarrhea, flatulence, muscle wasting, vomiting, and weight loss. Moreover, all patients were tested for anti-tTG antibodies with the Eu-tTG Quick test (refence 9113, lot 3368, Eurospital). ${ }^{8}$

Symptoms and signs of malabsorption in our RLS patients were uncommon (diarrhea in $14.3 \%$, flatulence in $3.6 \%$, abdominal pain in $1.8 \%$ ).

In our sample, only 2 patients affected by CD (1.8\%) were found: a woman (age 57 years; body mass index, 23.3; serum ferritin level, $9 \mathrm{ng} / \mathrm{mL}$; IRLSSG rating scale score = 18) positive for anti-tTG antibodies by the eu-tTG Quick Test (CD diagnosis confirmed by duodenal biopsy) and

*Correspondence to: Luigi Ferini-Strambi, Sleep Disorders Center, Università Vita-Salute San Raffaele, Milan, Italy; ferinistrambi.luigi@hsr.it.

Relevant conflicts of interest/financial disclosures: Nothing to report. This study was funded in part by NEURECA FONDAZIONEOnlus, an Italian nonprofit organization devoted to supporting research initiatives in movement disorders and sleep disorders.

Full financial disclosures and author roles may be found in the online version of this article.

Published online 7 April 2011 in Wiley Online Library (wileyonlinelibrary.com). DOI: 10.1002/mds.23615 another woman (age 74; body mass index, 18.0; serum ferritin level, $15 \mathrm{ng} / \mathrm{mL}$; IRLSSG rating scale score $=38$ ) whose Eu-tTG Quick test was negative because of a gluten-free diet, but with a previous diagnosis of CD confirmed by duodenal biopsy. No cause for the iron deficiency was found in these 2 cases other than CD. Both patients had a family history positive for RLS. The first patient had never received specific treatments for RLS, whereas the second patient had used only clonazepam ( $0.5 \mathrm{mg} /$ day) for several months without significant effect on her RLS symptoms.

In the first patient, a gluten-free diet and supplemental iron (4 treatments of $200 \mathrm{mg}$ of intravenous iron sucrose spread over 1 week) determined an increase in serum ferritin level to $46 \mathrm{ng} / \mathrm{mL}$ without any significant improvement in RLS symptoms (IRLSSG rating scale score $=15$ ). The second patient, already on a gluten-free diet, with the supplemental iron (5 treatments of $200 \mathrm{mg}$ of intravenous iron sucrose spread over 1 week) had an increase in serum ferritin $(39 \mathrm{ng} / \mathrm{mL})$ with a concomitant marked improvement in RLS (IRLSSG rating scale score $=13$ ).

The currently estimated prevalence of $\mathrm{CD}$ is $1 \%$, with a statistical range of probability of $0.5 \%-1.26 \%$ in the general population in Europe and the United States. ${ }^{6}$ In our sample of consecutive patients with RLS, the prevalence of CD was $1.8 \%$; thus, it is very difficult to state that $\mathrm{CD}$ is frequently associated with RLS. By observing our cases, we cannot conclude that gluten withdrawal determined an improvement in RLS symptoms. In both our patients we observed very low ferritin levels, and this seems to suggest that CD may be associated with RLS because of an association with iron deficiency. However, in a previous study in a CD population, ${ }^{2}$ we found lower hemoglobin levels in CD patients with RLS than in those without RLS, but no significant correlation between the presence of RLS and iron metabolism. Finally, the marked improvement observed in our second patient suggests that before providing specific treatments with dopaminergic compounds for RLS, a gluten-free diet and supplemental iron should be considered in patients with RLS plus CD.

Luigi Ferini-Strambi, MD, ${ }^{1 *}$ Sara Marelli, $\mathrm{PhD},{ }^{1}$ Marcello Moccia, MS, ${ }^{2}$ Roberto Erro, MD, ${ }^{2}$ Carolina Ciacci, $\mathrm{MD},{ }^{3}$ and Paolo Barone, $\mathrm{PhD}^{4}$

${ }^{1}$ Sleep Disorders Center and Division of
Neurosciences, Università Vita-Salute San
Raffaele, Milan, Italy; ${ }^{2}$ Department of
Neurological Sciences, University Federico II,
Naples, Italy; ${ }^{3}$ Department of Systematic
Pathology, University Federico II, Naples, Italy;
and ${ }^{4}$ Department of Neurological Sciences,
University Federico II, Naples, Italy

\section{References}

1. Weinstock LB, Walters AS, Mullin GE, Duntley SP. Celiac disease is associated with restless legs syndrome. Dig Dis Sci 2010;55. 1667-1673. 
2. Moccia M, Pellecchia MT, Erro R, et al. Restless legs syndrome is a common feature of adult celiac disease. Mov Disord 2010;25: 877-881.

3. Manchanda S, Davies CR, Picchietti D. Celiac disease as a possible cause for low serum ferritin in patients with restless legs syndrome. Sleep Med 2009;10:763-765.

4. Allen RP, Picchietti D, Hening WA, et al. Restless legs syndrome: diagnostic criteria, special considerations, and epidemiology. A report from the restless legs syndrome diagnosis and epidemiology workshop at the National Institutes of Health. Sleep Med 2003;4: 101-119.

5. The International Restless Legs Syndrome Study Group. Validation of the International Restless Legs Syndrome Study Group rating scale for restless legs syndrome. Sleep Med 2003;4:121-132.

6. Green PH, Cellier C. Celiac disease. N Engl J Med 2007;357: 1731-1743.

7. Tack GJ, Verbeek W, Schreurs MW, Mulder CJ. The spectrum of celiac disease: epidemiology, clinical aspects and treatment. Nat Rev Gastroenterol Hepatol 2010;7:204-213.

8. Korponay-Szabò IR, Szabados K, Pusztai J, et al. Population screening for coeliac disease in primary care by district nurses using a rapid antibody test: diagnostic accuracy and feasibility study. BMJ 2007;335: 1244-1247.

\section{Novel Mutations in Siblings with Later-Onset PLA2G6-Associated Neurodegeneration (PLAN)}

Mutations in the PLA2G6 gene were first described in individuals with infantile neuroaxonal dystrophy (INAD) in $2006^{1}$ and were later described in individuals presenting with dystonia and parkinsonism in the late teenage years and early adulthood. ${ }^{2,3}$ It has been proposed that the spectrum of neurodegenerative disorders related to mutations in the PLA2G6 gene be called "PLA2G6-associated neurodegeneration" (PLAN). ${ }^{4}$ We describe 2 siblings with MRI findings of cerebellar atrophy and brain iron accumulation and a clinical presentation consistent with the adult-onset dystonia-parkinsonism phenotype described in some reports.

\section{Patients and Methods}

Both siblings were born to nonconsanguineous parents of French, German, Irish, and English ancestry.

Sibling 1 first developed depression requiring hospitalization at age 18 but was able to complete 2 years of community college with a B average. Subsequently, she developed difficulty with mobility, a tendency to fall, and softened speech.

Her examination at age 20 revealed hypophonia, appendicular and axial rigidity, stooped posture with shuffling gait, accompanying dystonic posturing of her limbs, brisk reflexes, negative Babinksi, and positive Romberg. She is

*Correspondence to: Matthew A. Bower, Institute of Human Genetics, University of Minnesota, Minneapolis, Minnesota, USA; mbower1@fairview.org

Relevant conflicts of interest/financial disclosures: Nothing to report. Full financial disclosures and author roles may be found in the online version of this article.

Published online 25 April 2011 in Wiley Online Library (wileyonlinelibrary.com). DOI: 10.1002/mds.23617 currently 26 years old, and her course over the past 6 years has been marked by increasing rigidity, progressive hypophonia, and profound postural impairment.

Sibling 2 was reported to be normal until age 4, when she developed stuttered speech, dyslexia, and clumsiness. Behavioral difficulties such as poor eye contact and difficulty with authority figures were noted. Her motor skills stabilized with therapy through high school. At age 17, she developed psychiatric symptoms including delusions and paranoia. Her examination at age 23 years revealed a flat affect, a withdrawn demeanor with paucity of speech, hypophonia, and masked facies. She had saccadic pursuits without nystagmus and dystonic hand posturing. Her tone was increased with some accompanying contractures that reduced the range of motion. A fine distal hand tremor was present. Ankle reflexes were absent with negative Babinski. Her upper extremities were slow and dysmetric on targeted movements. The patient required support at all times while ambulating.

\section{PLA2G6 Testing Methods}

All 16 coding exons of the PLA2G6 gene were bidirectionally sequenced in sibling 1 . Sequencing of exon 2 was performed on parents and sibling 2 .

All family members were screened using multiplex ligation-dependent probe amplification (MLPA). Analysis was performed using SALSA MLPA kit P120 PANK2/PLA2G6 (MRC-Holland, Amsterdam, The Netherlands).

\section{Results Imaging}

T1-weighted MRI imaging demonstrated significant cerebellar atrophy in both siblings (Fig. 1B,D). T2-weighted
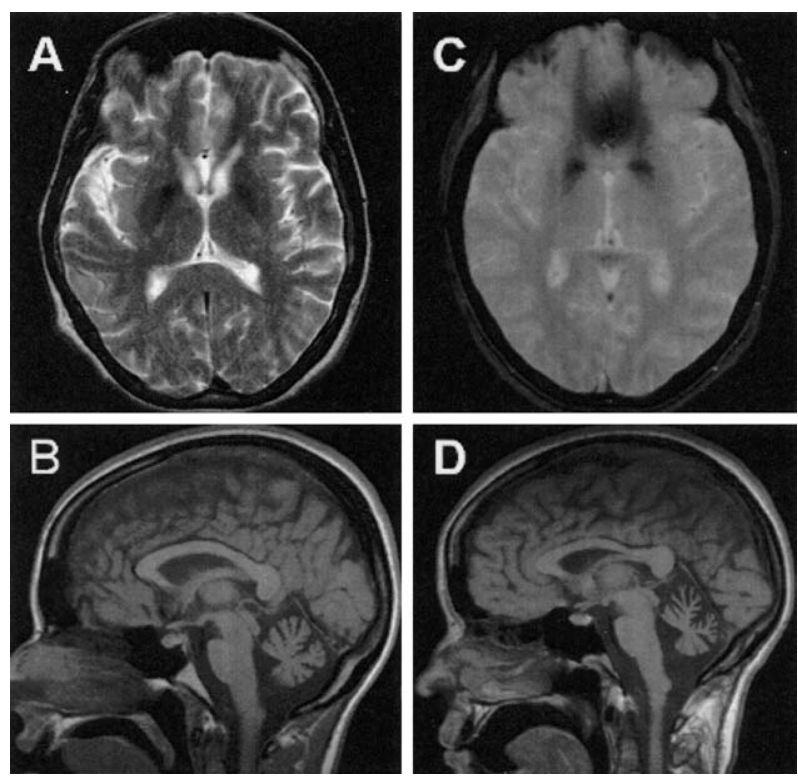

FIG. 1. MRI images for sibling 1 (A, B) and sibling 2 (C, D). A: T2 TSEweighted image showing bilateral hypointensity of basal ganglia in sibling 1. B: T1-weighted MRI showing midline cerebellar atrophy in sibling 1. C: $\mathrm{T}^{*}$-weighted image showing hypointensity of the basal ganglia in sibling 2. D: T1-weighted MRI showing midline cerebellar atrophy in sibling 2 . 
images demonstrated bilateral hypointensity of the globus pallidus in both siblings (Fig. 1A,C).

\section{PLA2G6 Testing}

Sequence analysis in both sisters revealed a heterozygous c. $4 \mathrm{C}>\mathrm{A}$ substitution in exon 2 of the PLA2G6 gene. This nucleotide change causes a substitution of lysine for a highly conserved glutamine at the second amino acid of the iPLA2VIA protein (p.Q2K).

MLPA analysis revealed a heterozygous deletion of exon 3 in both sisters. The deletion of exon 3 does not alter the reading frame of the remaining PLA2G6 transcript and is predicted to result in an in-frame deletion of amino acids 71-142.

Testing of the parents confirmed that these 2 mutations are present in the trans configuration in the siblings.

\section{Discussion}

We report 2 novel PLA2G6 mutations in siblings presenting with psychiatric and motor findings consistent with prior reports of PLA2G6-associated dystonia-parkinsonism. Both siblings had cerebellar atrophy and evidence of brain iron accumulation on MRI. These MRI findings have not been consistent in the limited number of later-onset PLAN patients described to date. ${ }^{2,3}$

A trend has been noted wherein later-onset PLAN disorders are associated with the presence of missense mutations. $^{2,3}$ To date, this is the first report of a later-onset PLAN phenotype associated with a large deletion in the PLA2G6 gene. That the exon 3 deletion leaves the remaining reading frame intact may contribute to the milder presentation in these siblings. Previously, whole-exon deletions have only been reported in the more severe infantile neuroaxonal dystrophy presentation of PLAN. ${ }^{5}$

One notable feature is the discrepancy in the age of onset of symptoms in the 2 siblings. This suggests that factors other than the PLA2G6 genotype may contribute to disease onset and progression.

Matthew A. Bower, MS, ${ }^{1, "}$ Khalaf Bushara, MD, MRCP, ${ }^{2}$ Melissa A. Dempsey, MS, ${ }^{3}$ Soma Das, PhD, ${ }^{3}$ and Paul J. Tuite, $\mathrm{MD}^{2}$

${ }^{1}$ Institute of Human Genetics and ${ }^{2}$ Department of Neurology, University of Minnesota, Minneapolis, Minnesota, USA; and ${ }^{3}$ Department of Human Genetics, University of Chicago, Chicago, Illinois, USA

\section{References}

1. Morgan NV, Westaway SK, Morton JEV, et al. PLA2G6, encoding phospholipase $A_{2}$, is mutated in neurodegenerative disorders with high brain iron. Nat Genet 2006;38:752-754.

2. Paisan-Ruiz C, Bhatia KP, Li A, et al. Characterization of PLA2G6 as a locus for dystonia-parkinsonism. Ann Neurol 2009; 65:19-23.

3. Paisan-Ruiz C, Abi L, Schneider SA, et al. Widespread Lewy body and tau accumulation in childhood and adult onset dystonia-parkinsonism cases with PLA2G6 mutations. Neurobiol Aging 2010 [Epub ahead of print].

4. Kurian MA, Morgan NV, Macpherson L, et al. Phenotypic spectrum of neurodegeneration associated with mutations in the PLA2G6 gene (PLAN). Neurology 2008;70:1623-1629.
5. Crompton D, Rehal PK, MacPherson L, et al. Multiplex ligation dependent probe amplification (MLPA) analysis is an effective tool for the detection of novel intragenic PLA2G6 mutations: implications for molecular diagnosis. Mol Gen Metab 2010;100:207-212.

\section{Opsoclonus-Myoclonus Syndrome and Exaggerated Startle Response Associated With Small-Cell Lung Cancer}

Opsoclonus-myoclonus syndrome (OMS) is a rare neurological disorder that is usually seen in conjunction with tumors (most commonly breast, lung, and gynecological), infections, or toxic-metabolic processes. In addition to opsoclonus and/or myoclonus, the clinical features of OMS may include ataxia and encephalopathy. ${ }^{1,2}$ We describe a patient who presented with OMS and a strikingly exaggerated startle response, prompting an evaluation for an underlying malignancy, which led to diagnosis of a small-cell lung carcinoma.

A 64-year-old woman presented with a 3-month history of dizziness and unsteadiness. Her symptoms began suddenly with an attack of dizziness and unsteadiness that lasted only a few seconds. The dizziness was described as a light-headed feeling without vertigo. Over the next few weeks, she had similar episodes, lasting longer and occurring more frequently, and eventually her symptoms became constant. Then, 2 weeks prior to her presentation, she developed "jumping" vision. The patient also had lost approximately 15 pounds over the past few months. She had a remote history of tobacco use. Before our evaluation she had a normal brain MRI.

On examination, the patient had bursts of back-to-back, multidirectional saccades, with variable amplitude (ie, opsoclonus), that were exacerbated during pursuit. The saccadic oscillations were also visible under closed eyelids (Video 1). She had occasional spontaneous myoclonic jerks of her head and a strikingly exaggerated startle response to sound and light that could be elicited even with expected stimuli (Video 2). Eye movements were otherwise remarkably intact. A subtle intention and postural tremor of her hands was present, as well as a slight dysmetria on finger-to-nose and heelto-shin testing, more on the left side. Her gait was wide based and mildly unsteady, and she could not walk in tandem unassisted. The remainder of her examination was normal.

Routine blood studies showed no abnormalities. Cerebrospinal fluid analysis was normal. Viral PCR including for West Nile

Additional Supporting Information may be found in the online version of this article.

*Correspondence to: David S. Zee, Department of Neurology, Johns Hopkins University School of Medicine, Baltimore, Maryland, USA; dzee@jhu.edu

Relevant conflicts of interest/financial disclosures: Nothing to report. Full financial disclosures and author roles may be found in the online version of this article.

Published online 30 March 2011 in Wiley Online Library (wileyonlinelibrary.com). DOI: 10.1002/mds.23626 


\section{References}

virus was negative. An EEG was within normal limits, and when she was startled, there was no EEG correlate to her myoclonic jerk apart from muscle artifact. A comprehensive serum paraneoplastic antibody panel (including, among others, anti-Ri, amphiphysin, -Yo, -CV2, and -Hu) was negative. A CT of the chest/abdomen/pelvis, mammograms, transvaginal ultrasound, and FDG-PET/CT were performed, and a 4.2-cm lung mass was found in the left lower lobe with involvement of 1 lymph node. A lung biopsy showed this to be a small-cell lung carcinoma. PET also revealed physiologically increased uptake in the cerebrum and in the cerebellar hemispheres, although more so in the latter. Treatment for the malignancy was initiated with combination chemotherapy and radiation therapy. Over the course of several months, her tumor shrunk, her ocular oscillations markedly improved, and her startle myoclonus disappeared.

Paraneoplastic neurological syndromes are considered to arise from an autoimmune response directed against neuronal antigens ectopically expressed by tumor cells. ${ }^{3}$ Specific autoantibodies have been associated with OMS, especially anti-Ri and antiamphiphysin, but most patients with OMS are seronegative for all known antineuronal antibodies, suggesting that cell-mediated immunity plays an important role. $^{2-4}$ Alternatively, there may be associated novel autoantibodies yet to be identified.

Localization of the lesion in OMS remains controversial, with evidence supporting 2 predominant theories. One hypothesis states that cerebellar dysfunction leads to disinhibition of the fastigial nucleus by the Purkinje cells, resulting in OMS. ${ }^{4}$ In our case, this hypothesis correlates well with the relative hypermetabolism of the cerebellar cortex revealed on PET and the beneficial action of clonazepam, but does not provide a plausible explanation of the augmented startle response. Another view is that the culprit is the caudal pontine reticular formation and represents either dysfunction of pause neurons that inhibit the burst neurons that drive saccades or primary hyperexcitability of the burst neurons themselves. ${ }^{5,6}$ The exaggerated startle response of our patient is consonant with the second hypothesis because the nucleus reticularis pontis caudalis plays an important role in the startle reflex, and therefore hyperexcitability of neurons here would account for her response. ${ }^{6}$ Finally, a caveat: an exaggerated startle response must be distinguished from reflex reticular myoclonus, a response that also originates in the caudal brain stem. ${ }^{7}$ Unfortunately, we could not perform tests to make this distinction at a time when our patient was symptomatic.

\section{Legends to the Videos}

Video 1: Spontaneous saccadic oscillations, also visible with closed eyes, exacerbated with pursuit. The movements occurred intermittently, and there did not appear to be an intersaccadic interval.

Video 2: Exaggerated startle with blinking of the eyes and flexion of the neck to expected and unexpected auditory (clap) and visual (light) stimuli.

Elias S. Sotirchos, MD, ${ }^{1}$ E. Ray Dorsey, MD, MBA, ${ }^{2}$ Ik Lin Tan, MBBS, ${ }^{2}$ and David S. Zee, $\mathrm{MD}^{2 *}$

\author{
${ }^{1}$ Medical School, National \& Kapodistrian, \\ University of Athens, Greece; ${ }^{2}$ Department of \\ Neurology, Johns Hopkins University School of \\ Medicine, Baltimore, Maryland, USA
}

1. Pranzatelli MR. The neurobiology of the opsoclonus-myoclonus syndrome. Clin Neuropharmacol 1992;15:186-228.

2. Ko MW, Dalmau J, Galetta SL. Neuro-ophthalmologic manifestations of paraneoplastic syndromes. J Neuroophthalmol 2008;28:58-68.

3. Gozzard P, Maddison P. Which antibody and which cancer in which paraneoplastic syndromes? Pract Neurol 2010;10:260-270.

4. Wong A. An update on opsoclonus. Curr Opin Neurol 2007;20:25-31.

5. Leigh RJ, Zee DS. The Neurology of Eye Movements. 4th ed. New York, NY:Oxford University Press; 2006.

6. Yonekawa T, Saito Y, Sakuma H, et al. Augmented startle responses in opsoclonus-myoclonus syndrome. Brain Dev 2010 [Epub ahead of print].

7. Brown P, Rothwell JC, Thompson PD, Britton TC, Day BL, Marsden CD. The hyperekplexias and their relationship to the normal startle reflex. Brain 1991;114:1903-1928.

\section{A Familial Case of Sleep Rhythmic Movement Disorder Persistent Into Adulthood; Approach to Pathophysiology}

Sleep-related rhythmic movement disorder (SRMD) encompasses a group of disorders characterized by stereotyped, repetitive, rhythmic movements involving different parts of the body emerging mainly during sleep onset. ${ }^{1}$ SRMD typically starts within the first 2 years of life and usually resolves by age $10 .^{1}$ Adult cases are not uncommon, ${ }^{2,3}$ but familial occurrence is very rare. The pathogenesis of SRMD probably varies, given the various phenomena ranging from "autoerotic," self-stimulatory behaviors during wake or sleep onset to more complex movements arising from stable sleep accompanied by sleep disruption that have been included under this category. However, cases studied with video-polysomnography (VPSG) have shown that some forms of SRMD constitute true movement disorders that emerge in relation to arousal events. ${ }^{3}$

To gather information about the pathophysiology of SRMD, we studied a familial case of SRMD in a 24-yearold man persistent since infancy. The episodes had been observed by his parents, as he had no recollection of the events on awakening. The patient complained about frequent mild head injuries during sleep, nonrestorative sleep, and daytime sleepiness. He was born after an uncomplicated gestation and labor and had a normal psychomotor development and cognitive profile. He was taking no medications and denied any alcohol or substance abuse. His neurological

Additional Supporting Information may be found in the online version of this article.

${ }^{*}$ Correspondence to: Anastasios Bonakis, Medical School, University of Athens, Department of Neurology, Eginition Hospital, Athens, Greece; bonakistasos@yahoo.com

Relevant conflicts of interest/financial disclosures: Nothing to report. Full financial disclosures and author roles may be found in the online version of this article.

Published online 29 April 2011 in Wiley Online Library (wileyonlinelibrary.com). DOI: 10.1002/mds.23627 
Table 1. Sleep data from second-night (clonazepam-free), third-night (clonazepam $0.25 \mathrm{mg}$ ), and fourth-night (clonazepam $0.5 \mathrm{mg}$ ) recordings as well as the number of rhythmic movement episodes, their total and longest duration, and their relation to REM stage

\begin{tabular}{lccc}
\hline & Second night & Third night & Fourth night \\
\hline SP & 533 & 530.5 & 588.5 \\
TST & 530.5 & 528.5 & 582.5 \\
SE (\%) & 96.2 & 95.2 & 96.9 \\
N1 \% of SP & 8.3 & 4.6 & 5.3 \\
N2 \% of SP & 59 & 58.5 & 52.3 \\
N3 \% of SP & 8.5 & 12.9 & 14.2 \\
REM \% of SP & 23.7 & 20.9 & 27.2 \\
W \% of SP & 0.5 & 3.1 & 1 \\
ARI & 15.5 & 11.9 & 15 \\
RMs, total number & 22 & 53 & 43 \\
RMs in REM & 15 & 43 & 42 \\
RMs related to arousal & 6 & 3 & 5 \\
TD (s) & 1259 & 497.8 & 163 \\
LD (s) & 460 & 54.9 & 10.9 \\
\end{tabular}

SP, sleep period; TST, total sleep time; SE, sleep efficiency; N1, sleep stage 1; N2, sleep stage 2; N3, slow-wave sleep; W, wake stage after sleep onset; ARI, arousal index; RMs, rhythmic movement episodes; TD, total duration of RMs; LD, longest duration of RMs. history, clinical examination, and brain MRI were unremarkable. Family history revealed a 57-year-old maternal uncle still suffering from SRMD and a maternal grandfather with lifelong restless sleep.

The patient underwent 4 consecutive full-night Videopolygraphic recordings. The first was a diagnostic VideoPSG, and the rest included 24-lead EEG recordings (the last 2 made after nighttime administration of clonazepam 0.25 and $0.5 \mathrm{mg}$, respectively). Sleep was scored in 30-second epochs according to the new AASM criteria. ${ }^{4}$ Video-PSG revealed body-rolling movements in stages 1 and 2 and REM sleep. Periodically, rhythmic movements of the right upper limb hitting the forehead were recorded (Video). No other sleep pathology was detected.

Sleep data from the second (clonazepam-free), third (clonazepam $0.25 \mathrm{mg}$ ), and fourth (clonazepam $0.5 \mathrm{mg}$ ) night recordings as well as information (number, duration, etc.) about the rhythmic movement episodes (RMs) are presented in Table 1.

During the clonazepam-free night record, most RMs occurred in REM sleep. The RMs in REM sleep were similar to those in non-REM sleep (NREM), but their duration was very brief (from 4 to 20 seconds) compared with those reported in NREM sleep (from 16 to 460 seconds) (Video, Fig. 1a). The majority of RMs that took place during NREM were preceded by an arousal. However, there were RMs that emerged from stable stage 2 sleep (Fig. 1b). In
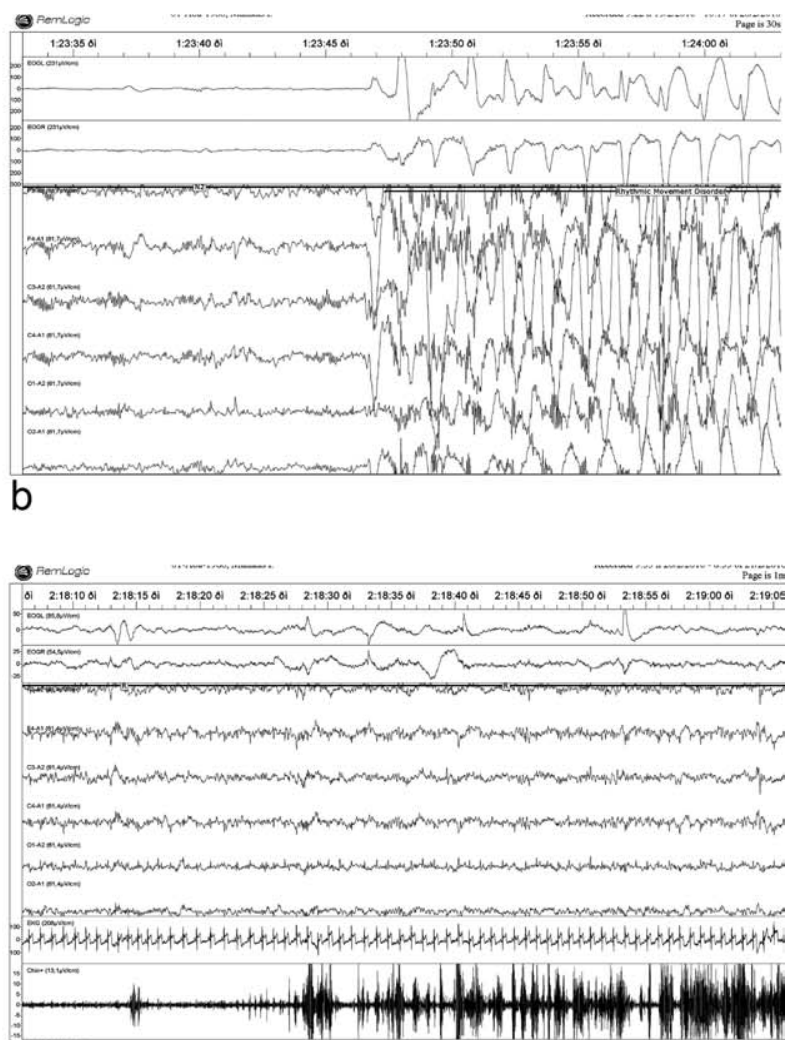

C

FIG. 1. a: Short, rhythmic movement episode in REM sleep (30-second epoch, 2-upper-channel electrooculogram, 6-channel electroencephalogram; EKG, electrocardiogram; chin, electrocardiogram of submentalis muscle). b: Rhythmic movement episode emerging from stable sleep stage 2 (30-second epoch, 2-upper-channel electrooculogram, 6-channel electroencephalogram). c: Two epochs, 60 seconds each, of REM sleep with prolonged lack of muscle atonia as recorded from submentalis muscle (chin). The first epoch includes respiratory effort channels (abdomen, thorax), airflow (thermistor), and electromyography from left and right tibialis anterior muscles. The increased muscle tone is not related to an arousal stimulus. 
contrast, almost no RMs emerging during REM were preceded by arousal. Concomitantly with the rhythmic movements, various other nonrhythmic movements (myoclonic or periodic) were apparent in stages 1-2, sometimes causing arousals followed by an RM (Video).

During REM sleep, periods of increased muscle tone unrelated to arousal stimuli were observed (Fig. 1c). This phenomenon of REM without atonia is characteristic of REM sleep behavior disorder (RBD). REM without atonia has been reported in SRMD cases persistent beyond infancy. ${ }^{5}$ Furthermore, RMD-like movements may emerge during episodes of RBD. ${ }^{6}$ In our case, it was clear that the patient did not have $\mathrm{RBD}$, given that he did not exhibit dream enactment behavior, and the movements in REM sleep were of the body-rolling type, similar to those in NREM sleep.

After the administration of clonazepam, the number of RMs in NREM sleep decreased markedly, with the patient spending more time in slow-wave sleep (SWS). The patient reported enhanced functioning during daytime and feeling more refreshed on awakening. The increased SWS probably relates to the decrement of RMs, which results in less disrupted NREM sleep. Hence, the observed increase of SWS is an indirect effect of clonazepam. In contrast, the RMs significantly increased in REM sleep, leading to a higher total number of RMs compared with the clonazepam-free recording; however, the brevity of the events during REM sleep led to a marked reduction of the average and longest duration of the RMs. It seems that clonazepam had no effect on RMs emerging in REM sleep. After 1 year of follow-up, the patient continues to experience more restorative sleep and brief RMs despite the increment of clonazepam, up to $1 \mathrm{mg} / \mathrm{night}$.

\section{Legends to the Video}

Video Segment 1. An episode of body rolling accompanied by rhythmic movement of the right upper limb during NREM stage 2 sleep.

Video Segment 2. An episode of body rolling preceded by a myoclonic jerk of the right latissimus dorsi muscle in stage 2 sleep.

Video Segment 3. Short-in-duration rhythmic movements in REM sleep.

Acknowledgments: We thank the sleep technicians of Evangelismos Hospital Sleep Center.

\footnotetext{
Anastasios Bonakis, MD, PhD, ${ }^{1 *}$ Ilia Kritikou, MD, ${ }^{2,3}$ Emmanouil Vagiakis, MD, ${ }^{4}$ Serafim Nanas, MD, ${ }^{4}$ and Sokratis G. Papageorgiou, $\mathrm{MD}, \mathrm{PhD}^{1}$

${ }^{1}$ Medical School, University of Athens, Department of Neurology, Eginition Hospital, Athens, Greece; ${ }^{2}$ Medical School, University of Athens, Department of Psychiatry, Eginition Hospital, Athens, Greece; ${ }^{3}$ College of Medicine, Penn State University, Psychiatry Department, Sleep Research and Treatment Center, Hershey, Pennsylvania, USA; and ${ }^{4}$ Evangelismos Hospital, Critical Care and Pulmonary Services, Center of Sleep Disorders, Athens, Greece
}

\section{References}

1. American Academy of Sleep Medicine. ICSD-2. International Classification of Sleep Disorders, 2nd ed. Diagnostic and Coding Manual. Newton, MA: American Academy of Sleep Medicine; 2005 .

2. Mayer G, Wilde-Frenz J, Kurella B. Sleep related rhythmic movement disorder revisited. J Sleep Res 2007;16:110-116.

3. Manni R, Terzaghi M, Sartori I, Veggiotti P, Parrino L. Rhythmic movement disorder and cyclic alternating pattern during sleep: a video-polysomnographic study in a 9-year-old boy. Mov Disord 2004;19:1186-1190

4. Iber C, Ancoli-Israel S, Chesson AL, Quan SF. The AASM Manual for the Scoring of Sleep and Associated Events: Rules, Terminology, and Technical Specifications.Westchester, IL: American Academy of Sleep Medicine; 2007.

5. Stepanova I, Nevsimalova S, Hanusova J. Rhythmic movement disorder in sleep persisting into childhood and adulthood. Sleep 2005;28: 851-857.

6. Manni R, Terzaghi M. Rhythmic movements in idiopathic REM sleep behavior disorder. Mov Disord 2007;22:1797-1800.

\section{LRRK2 G2019S Mutations May Be Increased in Puerto Ricans}

We read with interest the article by Shino et al that reported a higher familial aggregation of Parkinson's disease (PD) among Hispanics. ${ }^{1}$ In their evaluation of incident PD cases in northern California, they propose that there is an increased rate of genetic and/or shared environmental factors in this group. We are interested in identifying genetic risk factors among Hispanics in the United States and performed a pilot study of the LRRK2 G2019S mutation in Hispanic, non-Hispanic, and non-Jewish white subjects participating in genetics research at Beth Israel Medical Center in New York, who were seen initially as patients or self-referred for genetic studies. Our pilot work suggests that there may be a higher rate of G2019S mutations in Puerto Ricans, and supports that further evaluation of this population is warranted.

We analyzed G2019S mutations in 104 individuals who met strict criteria for idiopathic PD. ${ }^{2}$ Nineteen were of Hispanic descent, and 8 of these were of Puerto Rican background. Eighty-five were non-Hispanic, non-Jewish whites. Three cases with the LRRK2 G/A mutation (2.85\%) were identified. Two were of Puerto Rican descent, constituting $25 \%$

*Correspondence to: Rachel Saunders-Pullman, Department of
Neurology, Beth Israel Medical Center, New York, NY, USA; rsaunder@bethisraelny.org

Relevant conflicts of interest/financial disclosures: Nothing to report. This work was supported by research grants from the National Institute of Neurological Disorders and Stroke (K23NS047256, to R.S.-P.) and the Thomas Hartman Foundation for Parkinson's Research.

Full financial disclosures and author roles may be found in the online version of this article.

Published online 29 March 2011 in Wiley Online Library (wileyonlinelibrary.com). DOI: 10.1002/mds.23632 
Table 1. Demographics and mutation frequency

\begin{tabular}{|c|c|c|c|c|c|}
\hline & $\begin{array}{l}\text { All subjects } \\
(n=104)\end{array}$ & $\begin{array}{l}\text { All Hispanics } \\
\quad(n=19)\end{array}$ & $\begin{array}{l}\text { Puerto Ricans } \\
\qquad(\mathrm{n}=8)\end{array}$ & $\begin{array}{l}\text { Non-Puerto Rican } \\
\text { Hispanics }(n=11)\end{array}$ & $\begin{array}{c}\text { Non-Hispanic } \\
\text { whites }(n=85)\end{array}$ \\
\hline Sex, \% female (n) & $50.96 \%(53)$ & $52.63 \%(10)$ & $60 \%(6)$ & $47.06 \%(8)$ & $50.59 \%(43)$ \\
\hline Age at PD onset, mean $\pm S D^{a}$ & $53.37 \pm 12.31$ & $54.58 \pm 12.90$ & $54.0 \pm 12.32$ & $55.0 \pm 13.89$ & $53.09 \pm 12.23$ \\
\hline LRRK2 mutation, \% positive (n) & $2.88 \%(3)$ & $10.53 \%(2)$ & $25 \%(2)$ & $0 \%(0)$ & $1.18 \%(1)$ \\
\hline Family history of $P D^{b}$ & $31.37 \%$ (32 of 102$)$ & $22.22 \%$ (4 of 18$)$ & $25 \%$ (2 of 8 ) & $20 \%(2$ of 10$)$ & $33.33 \%$ (28 of 84$)$ \\
\hline
\end{tabular}

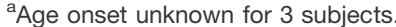

bProband reported family history of Parkinson disease in first-, second-, or third-degree relatives; data not available for 3 subjects.

(2 of 8 ) of all Puerto Ricans sampled. Both Puerto Rican cases were women, with onset at ages 53 and 42 years. The latter had an uncle with PD, and the former did not have a family history of parkinsonism. They were not known to be related. The third case was a man of Irish/German background, with onset at age 58 and a brother with PD. The frequency of mutations was greater in Puerto Ricans than in non-Puerto Ricans $(25.0 \%$ vs $1.0 \%$, Fischer's exact test, $P=.01)$. Mean age at onset and sex did not differ between groups (Table 1). In a logistic regression model adjusting for age at onset of PD, the odds of carrying a G2019S mutation was still greater in the Puerto Rican PD cases compared with in non-Puerto Ricans, although the confidence intervals were broad $(\mathrm{OR}=28.24$; 95\% CI, 2.16368.67; $P=.011$ ). While there was a trend, the difference in PD between all Hispanics $(11.1 \%)$ and non-Hispanic whites $(1.16 \%)$ was not significant.

Puerto Ricans may be of Spanish, Taino, and Black African descent, and a genetic admixture is not uncommon. ${ }^{3}$ The relative admixture in our cases was not known. Spanish colonization and immigration to Puerto Rico as well as Ashkenazi Jewish influence may contribute to the increased rate of G2019S mutations, as this mutation is increased in Spaniards ${ }^{4}$ as well as in Ashkenazi Jews. ${ }^{2}$ It is of interest that a prior North American screen identified 2 cases with LRRK2 mutations among 20 Hispanic individuals screened, 1 with the G2019S mutation and 1 with the R1441G mutation. ${ }^{5}$ Of note, the Consortium of Risk for Early Onset Parkinson Disease (CORE-PD), a multicenter study of subjects with PD onset younger than 51 years, did not report an increased rate of LRRK2 G2019S mutations in Hispanics overall. However, both of the Hispanic mutation-positive cases were Puerto Rican, ${ }^{6}$ and the subtotal of Puerto Rican cases was not indicated. LRRK2 mutations do not appear to be at increased frequency in Mexicans. $^{7}$

We did not screen for other LRRK2 mutations, including the R1441G mutation, which is increased in Spaniards of Basque origin. ${ }^{4}$ As descendants from the latter group settled in California and the Southwest, it is possible that this other LRRK2 mutation may also account for increased rates in US Hispanics. Further, some of the increased familial aggregation noted in Hispanics may be due to parkin mutations, as these are increased in Hispanics in the United States. ${ }^{6}$

The main limitation to our pilot data is the small number of Puerto Ricans sampled. However, our rate of G2019S mutation carriers in non-Jewish whites is similar to that in other such mixed populations that include both sporadic and familial PD and early- and late-onset PD. Thus, further evaluation for LRRK2 mutations in Hispanic populations in the United States should be considered in both early- and late-onset cases, as these may constitute an important etiology of PD, particularly among Puerto Ricans.

Rachel Saunders-Pullman, MD, MPH, ${ }^{1,2 *}$ Jose Cabassa, MD, ${ }^{1}$ Marta San Luciano, $\mathrm{MD},{ }^{3}$

Kaili Stanley, BS, ${ }^{1}$ Deborah Raymond, MS, ${ }^{1}$

Laurie J. Ozelius, $\mathrm{PhD},{ }^{4}$ and Susan B. Bressman, $\mathrm{MD}^{1,2}$

${ }^{1}$ Department of Neurology, Beth Israel Medical Center, New York, NY, USA; ${ }^{2}$ Department of Neurology, Albert Einstein College of Medicine, Bronx, NY, USA; ${ }^{3}$ Department of Neurology, State University of New York, Downstate College of Medicine, Brooklyn, NY, USA; and

${ }^{4}$ Department of Neurology and Department of

Genetics and Genomic Sciences, Mount Sinai School of Medicine, New York, NY, USA

\section{References}

1. Shino MY, McGuire V, Van Den Eeden SK, et al. Familial aggregation of Parkinson's disease in a multiethnic community-based case-control study. Mov Disord.2010,25:2587-2594.

2. Ozelius LJ, Senthil G, Saunders-Pullman R, et al. LRRK2 G2019S as a cause of Parkinson's disease in Ashkenazi Jews. N Engl J Med. 2006;354:424-425.

3. Tang H, Choudhry S, Mei R, et al. Recent genetic selection in the ancestral admixture of Puerto Ricans. Am J Hum Genet. 2007;81: 626-633.

4. González-Fernández MC, Lezcano E, Ross OA, et al. LRRK2-associated parkinsonism is a major cause of disease in Northern Spain. Parkinsonism Relat Disord. 2007;13:509-515.

5. Deng $\mathrm{H}$, Le W, Guo Y, et al. Genetic analysis of LRRK2 mutations in patients with Parkinson disease. J Neurol Sci. 2006;251: 102-106.

6. Alcalay RN, Caccappolo E, Mejia-Santana H, et al. Frequency of known mutations in early-onset Parkinson disease. Implication for genetic counseling: the Consortium on Risk for Early Onset Parkinson Disease Study. Arch Neurol. 2010;67:1116-1122.

7. Yescas P, Lopez M, Monroy N, et al. Low frequency of common LRRK2 mutations in Mexican patients with Parkinson's disease. Neurosci Lett. 2010;485:79-82. 


\section{Familial 7q21.3 Microdeletion Involving Epsilon-Sarcoglycan Causing Myoclonus Dystonia, Cognitive Impairment, and Psychosis}

The most common genetic cause of myoclonus dystonia is a heterozygous mutation or deletion in the gene epsilonsarcoglycan (SGCE), which is present in $20 \%-80 \%$ of patients. ${ }^{1-3}$ The classic phenotype is early-onset (mean, 6 years) upper body myoclonus and dystonia to a lesser extent. ${ }^{1}$ Associated emotional disorders are common, and psychosis has been occasionally described. ${ }^{1,4-6}$ Although the majority of SGCE mutations can be detected using direct sequencing, large deletions of SGCE can cause myoclonus dystonia that require detection using assays that detect copynumber variants and gene dosage. ${ }^{1,3,7}$ We report an unusual family with a $0.17-\mathrm{Mb}$ microdeletion resulting in $90 \%$ loss of SGCE whose members had myoclonus dystonia, cognitive impairment, and psychosis.

Case III:1 (Fig. 1) is a 17-year-old female who had mild language delay in early childhood. She walked at 18 months, but her gait was awkward, and she tripped excessively. Since her third year, she has experienced large-amplitude myoclonus of the arms and trunk that is intermittent and increases during stress and in social situations. She has cognitive impairment, with a full-scale IQ of 69, verbal IQ of 65, verbal comprehension IQ of 70, performance IQ of 78, and perceptual organization of 85 (WISC III). She has occasional panic attacks but does not fulfill a psychiatric diagnosis using DSM-IV criteria. Examination of her gait demonstrates symmetrical dystonic posturing of the feet, but no postural dystonia. There was no myoclonus evident on examination on 2 separate examinations. Case III:2, a 15-year-old female, also had mild developmental delay. She requires extra support at school but has never had formal psychometric testing. From the age of 2, she had awkward walking, with dystonic posturing of the feet exaggerated by stress. She also has intermittent myoclonic jerks of the upper limbs and trunk, although less than her sister. Case II:3, the father of the index cases, now 50 years of age, has never had cognitive impairment or movement disorders. At age 38, he developed acute-onset paranoia that people were watching him, talking about him, and "out to get him." $\mathrm{He}$ denied auditory hallucinations. He had religious preoccupations and was given a diagnosis of paranoid schizophrenia. He has taken risperidone since that time and has never returned to work, but remains in the family home. The extended family is notable for the high incidence of psychosis (Fig. 1). Case II:1, now age 54 years, was diagnosed with schizophrenia in his thirties, continues to have delusional beliefs, does not

Additional Supporting Information may be found in the online version of this article.

${ }^{*}$ Correspondence to: Russell C. Dale, Institute of Neuroscience and Muscle Research Children's Hospital at Westmead University of Sydney, Sydney, Australia; russelld@chw.edu.au

Relevant conflicts of interest/financial disclosures: Russell C. Dale has a University of Sydney postdoctoral fellowship.

Published online 21 March 2011 in Wiley Online Library (wileyonlinelibrary.com). DOI: 10.1002/mds.23639 work, and is resident in a home for people with mental health problems. Case II:5, now age 47 years, presented with delusions, hallucinations, and self-harm and was diagnosed with schizophrenia in her thirties. She continues to take antipsychotics but lives independently. Case II:6, now age 46 years, was diagnosed with schizophrenia in her thirties but refused to medicate herself, yet maintains living independently. Using a Sureprint G3Hmn Comparative Genomic Hybridization (CGH) $2 \times 400 \mathrm{~K}$ microarray with effective resolution of $0.06 \mathrm{Mb}$, a deletion was found on chromosome 7 , band q21.3. The microdeletion had a minimum size of $0.17 \mathrm{Mb}$ and extended from position 93.93 to 94.10 Mb. This deletion involves 2 genes only, CASD1 (whole gene deleted) and SGCE (90\% deleted), and was found in both index cases (III:1 and III:2) and in their father (II:3). The CGH microarray was normal in the mother of the index cases.

This family represents a further example of paternally inherited myoclonus dystonia from large deletions of SGCE. ${ }^{3}$ Only assays that can detect alterations in gene dosage will detect these large mutations. ${ }^{3}$ The contiguous gene CASD1 was also deleted, but CASD1 has no known function at a molecular level, or in human disease. ${ }^{7}$ The movement disorder was surprisingly mild in the index cases. The more pressing concern for the family was the cognitive impairment in the index cases and the familial psychosis. The father, despite carrying the same deletion as his daughters, denied any history of movement disorder, but instead presented with a psychotic illness in his thirties. His family history is remarkable for the high incidence of psychosis in his siblings, although these extended family members were unavailable for SGCE testing. It is theoretically possible that this familial psychosis is due to another, unidentified gene. However, given that epsilon-sarcoglycan is a brain protein and that SGCE mutations can result in psychiatric disease (including psychosis), we suspect that this microdeletion may represent the genetic risk factor for psychosis in this family. ${ }^{1,4-6}$

Acknowledgments: We thank Mr. Artur Darmanian (Cytogenetics, CHW) for his critical involvement in the microarray test procedure. We thank the family for consenting to this reponrt.

\author{
Russell C. Dale, PhD, ${ }^{1 *}$ Julian J. Nasti, MBBS, ${ }^{2}$ \\ Greg B. Peters, $\mathrm{PhD}^{3}$ \\ ${ }^{1}$ Institute of Neuroscience and Muscle Research \\ Children's Hospital at Westmead \\ University of Sydney, Sydney, Australia; ${ }^{2}$ Nepean \\ Hospital, University of Sydney \\ Sydney, Australia; ${ }^{3}$ Department of Cytogenetics \\ Children's Hospital at Westmead \\ University of Sydney, Sydney, Australia
}

\section{References}

1. Kinugawa K, Vidailhet M, Clot F, et al. Myoclonus-dystonia: an update. Mov Disord 2009;24:479-489.

2. Zimprich A, Grabowski M, Asmus F, et al. Mutations in the gene encoding epsilon-sarcoglycan cause myoclonus-dystonia syndrome. Nat Genet 2001;29:66-69.

3. Grunewald A, Djarmati A, Lohmann-Hedrich K, et al. Myoclonusdystonia: significance of large SGCE deletions. Hum Mutat 2008; 29:331-332. 


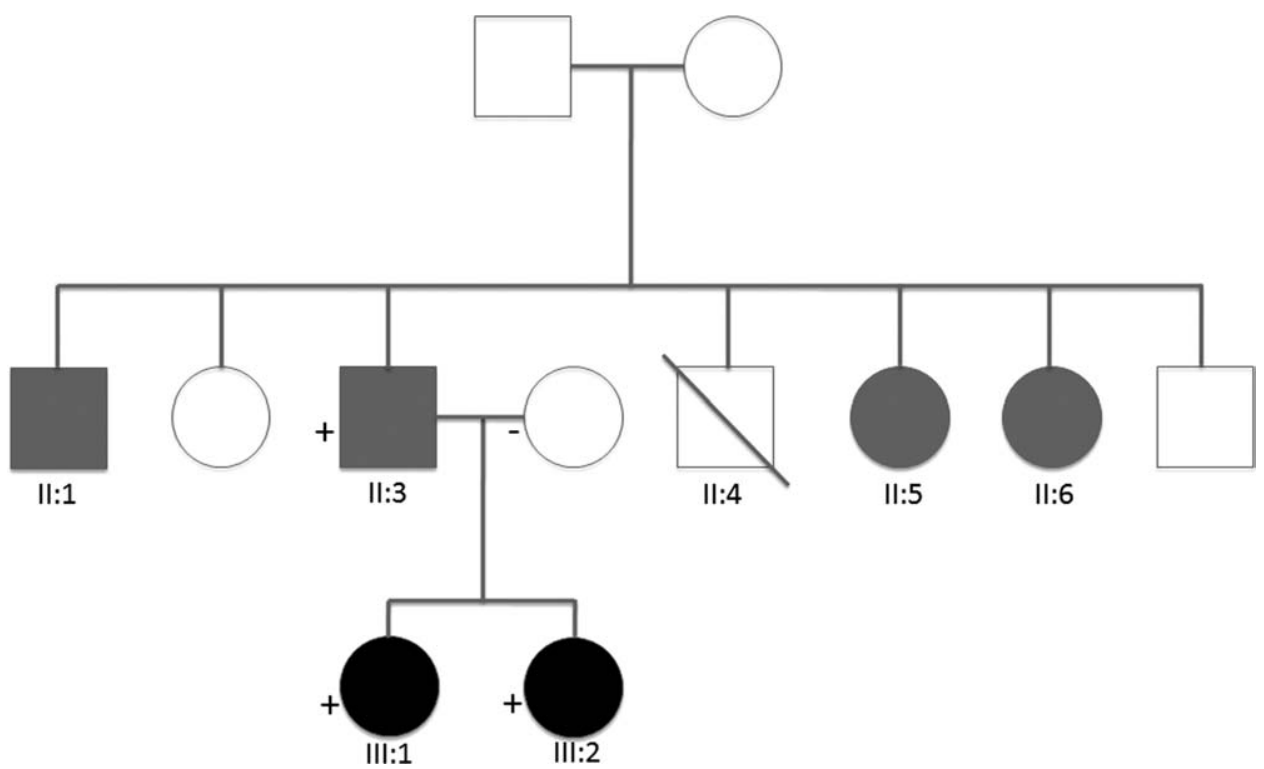

FIG. 1. Family tree demonstrating index cases with SGCE deletion (III:1 and III:2) who had cognitive impairment and mild myoclonus dystonia (black fill). The father of index cases had the same SGCE deletion (Il:3) but had adult-onset psychosis without myoclonus dystonia. Three of his siblings had a history of psychosis without movement disorders (II:1, Il:5, and II:6), but were unavailable for clinical examination or SGCE testing.

4. Wong SH, Steiger MJ, Larner AJ, Fletcher NA. Hereditary myoclonus dystonia (DYT11): a novel SGCE gene mutation with intrafamilial phenotypic heterogeneity. Mov Disord 2010;25: 956-957.

5. Misbahuddin A, Placzek M, Lennox G, Taanman JW, Warner TT. Myoclonus-dystonia syndrome with severe depression is caused by an exon-skipping mutation in the epsilon-sarcoglycan gene. Mov Disord 2007;22:1173-1175.

6. Doheny DO, Brin MF, Morrison CE, et al. Phenotypic features of myoclonus-dystonia in three kindreds. Neurology 2002;59: $1187-1196$.

7. Asmus F, Hjermind LE, Dupont E, et al. Genomic deletion size at the epsilon-sarcoglycan locus determines the clinical phenotype. Brain 2007;130:2736-2745.

\section{Singular DYT6 Phenotypes in Association with New THAP1 Frameshift Mutations}

DYT6 dystonia is an autosomal dominant disorder with incomplete penetrance $(\approx 60 \%)$ characterized by early-age onset (median, 13 years) and slight female predominance. ${ }^{1}$ The upper limb is a common site of onset, with progressive extension of the disease to other body parts. The cranial region is affected in almost two thirds of patients, and the functional repercussions of the disease are perceived by patients as mainly a result of disturbances in this region and particularly to the speech problems present in more than half of the patients; functional impairment is moderate overall (patients remain ambulatory). THAP1 gene mutations have now been identified in numerous DYT6 families. Here we describe 2 new THAP1 mutations identified in non-Amish patients with primary non-DYT1 dystonia.

Patients were selected among those followed in outpatient clinics by trained neurologists from the French Dystonia network. Eight index patients were recruited from Polish outpatient clinics through an international collaboration. A set of 178 independent index patients with primary non-DYT1 dys- tonia were included. Patients with a mean age at onset of $20.4 \pm 16.7$ years were diagnosed as having "generalized, segmental, or multifocal dystonia" (54\% of patients), or "oromandibular or cervical dystonia" $(21.3 \%)$. Moreover, as clinical expression of DYT6 has been redefined as "broad and overlapping with non-DYT6 dystonia subtypes,"2 we also included patients with "blepharospasm" (7.3\%) or with "other focal dystonia" such as writer's cramp (17.4\%). Sixtythree percent were isolated cases, and autosomal dominant transmission with sometimes incomplete penetrance was observed in families. Informed consent and blood samples were collected and DNA extracted from peripheral lymphocytes according to standard procedures. Direct sequencing of the 3 THAP1 coding regions and their exon boundaries was carried out. In the group of "generalized, segmental, or multifocal dystonia," we identified 2 novel THAP1 heterozygous mutations (c.377_378delCT deletion [p.Pro126ArgFsX2] in patient 1; c.514dupA insertion [p.Arg172LysFsX7] in patient 3) (Supplementary Figure 1). The same THAP1 deletion was identified in the dystonic sibling of patient 1 (patient 2). These new frameshift mutations result in the formation of premature STOP codons at positions 127 and 178,

*Correspondence to: Gwenaelle Collod-Béroud, INSERM, U827, Montpellier, France; gwenaelle.collod-beroud@inserm.fr Arnaud Blanchard and Agathe Roubertie contributed equally to this work.

Relevant conflicts of interest/financial disclosures: Nothing to report. This study was supported by grants from the French Ministry of Health (National PHRC 2007-A00614-49), AMADYS-LFCD, Alliance France Dystonie, Lions Club, French Dystonia Network, Université Montpellier 1 and INSERM. Arnaud Blanchard and Vuthy Ea are supported by a grant from the Ministère de l'Enseignement Supérieur et de la Recherche (MESR).

Full financial disclosures and author roles may be found in the online version of this article.

Published online 25 April 2011 in Wiley Online Library (wileyonlinelibrary.com). DOI: 10.1002/mds.23641 
Table 1. Clinical characteristics of carriers of THAP1 mutations

\begin{tabular}{|c|c|c|c|c|c|}
\hline & Patient 1 & Patient 2 & Patient 3 & Amish families ${ }^{*} n=25$ & Non-Amish patients ${ }^{\star \star} \mathrm{n}=50$ \\
\hline Sex & $\mathrm{F}$ & M & M & F $15(60 \%)$ & F 30 (60.0\%) \\
\hline Age at onset (y) & 4 & 7 & 9 & Median, 14.5 (5-38) & $2-62$ \\
\hline Age at last examination (y) & 52 & 50 & 38 & Median, 40 (10-66) & $13-79$ \\
\hline Family history & + & + & No & 1 & 0.656 \\
\hline $\begin{array}{l}\text { Site at onset } \\
\text { Upper limb } \\
\text { Lower limb } \\
\text { Cervical } \\
\text { Cranial }\end{array}$ & + & + & + & $\begin{array}{c}11(44 \%) \\
1(4 \%) \\
5(20 \%) \\
8(32 \%)\end{array}$ & $\begin{array}{c}48 \text { patients }^{\mathrm{a}} \\
28 \text { of } 48(58.3 \%) \\
5 \text { of } 48(10.4 \%) \\
6 \text { of } 48(12.5 \%) \\
12 \text { of } 48(25.0 \%)\end{array}$ \\
\hline $\begin{array}{l}\text { Site at examination } \\
\text { Upper limb } \\
\text { Lower limb } \\
\text { Cervical } \\
\text { Cranial } \\
\text { Speech }\end{array}$ & $\begin{array}{l}+ \\
+ \\
++ \\
+ \\
+\end{array}$ & $\begin{array}{l}+ \\
+ \\
+ \\
+ \\
+\end{array}$ & $\begin{array}{l}+ \\
\text { No } \\
+ \\
\text { No } \\
\text { No }\end{array}$ & $\begin{array}{l}22(88 \%) \\
12(48 \%) \\
14(56 \%) \\
17(68 \%) \\
16(64 \%)\end{array}$ & $\begin{array}{c}41 \text { patients }^{\mathrm{b}} \\
35 \text { of } 41(85.4 \%) \\
22 \text { of } 41(53.7 \%) \\
29 \text { of } 41(70.7 \%) \\
27 \text { of } 41(65.8 \%) \\
28 \text { of } 50(56.0 \%)\end{array}$ \\
\hline Distribution & G & G & S & $\begin{array}{l}\text { Fo: } 3(12 \%) \\
\text { S: } 10(40 \%) \\
\text { Mu: } 4(16 \%) \\
\text { G: } 8(32 \%)\end{array}$ & $\begin{array}{l}\text { Fo: } 10 / 50(20.0 \%) \\
\text { S: } 14 / 50(28.0 \%) \\
\text { Mu: } 2 / 50(4.0 \%) \\
\text { G: } 24 / 50(48.0 \%)\end{array}$ \\
\hline
\end{tabular}

Sex: F, female; M, male. Dystonia distribution: G, generalized; Fo, focal; Mu, multifocal; S, segmental.

${ }^{*} 4$ Families, 25 patients. ${ }^{1}$

**21 Families, 11 sporadic cases, 50 patients including our 3 patients. ${ }^{2,4-8}$

${ }^{a} 48$ Patients, as data were not available for patients reported by Djarmati et al. ${ }^{6}$

${ }^{b} 41$ Patients, as data were not available for patients reported by Houlden et al. ${ }^{7}$

respectively, and suggest, as previously reported, a loss-offunction mechanism by haploinsufficiency.

The clinical picture of these 3 patients (Table 1 ) fits with the clinical phenotype associated with THAP1 mutations, but some clinical aspects are singular. In patient 3, dystonia initially implicated the right upper limb at the age of 9, with progressive axial involvement; at 14 years of age, the right upper limb and the cervical region were clearly dystonic, with writer's cramp and torticolis. The patient was not treated. At the age of 18 the patient reported spontaneous, complete remission (cervical and upper limb). This remission was transient, and after a free interval of 4 years, without any obvious triggering factor, dystonia rapidly recurred with right arm and cervical involvement. Afterward, dystonia did not spread to other body parts; upper limb dystonia remained moderate and stable, and disability was mainly due to cervical involvement. No worsening or remission has been reported since the age of 22, except for partial improvement after trihexiphenydyl treatment and botulinum toxin injections in the neck. Such transient improvement, or "honeymoon," is not uncommon in other primary dystonias, particularly in cervical dystonia, ${ }^{3}$ but usually occurs within the first 5 years after onset. To our knowledge, such a honeymoon has never been observed in other known DYT6 patients.

Patient 1 is remarkable because of the lower limb onset of the disease at an early age, thus mimicking DYT1 dystonia. Nevertheless, upper limb onset is reported in more than half of DYT6 patients, and cranial onset occurs in one quarter of the cases (Table 1). In patients 1 and 2, who are siblings, dystonia became progressively generalized, with prominent cranial involvement, as described in almost half the DYT6 patients reported in the literature.
Although the 3 patients did not report any family history of motor disabilities or movement disorders (except for the sibling of patient 1), unfortunately, other family members could not be examined or tested for THAP1 mutations. Patient 3 was thus considered a sporadic case.

The occurrence of cognitive and psychiatric disorders is an area of uncertainty in rare genetic forms of dystonia. Standardized cognitive and psychiatric assessments were not performed in our 3 patients; they were all university graduates, and their past medical histories was uneventful for psychiatric disturbances. Paisan-Ruiz ${ }^{4}$ reported cognitive changes in 1 DYT6 patient. Cognitive or psychiatric functions among THAP1 mutation carriers will need to be better analyzed.

In conclusion, THAP1 implication in primary dystonia is rare in non-Amish patients (about $1.5 \%$ of tested dystonic patients reported in the literature). The DYT6 phenotype overlaps with that of other forms of primary early-onset dystonia, especially DYT1 dystonia. Good candidates for THAP1 screening might be patients with onset in childhood or during adolescence who present cervicocranial and upper limb involvement or generalized dystonia and cranial involvement.

Acknowledgments: We thank all patients and family members for participation in this study.

Note that during the reviewing process, several new THAP1 mutations were reported (Zittel et al, Groen et al., Söhn et al, Cheng et al, and De Carvalho et al).

Arnaud Blanchard, MS, 1,2 Agathe Roubertie, MD, PhD, 1,2,3 Marion Simonetta-Moreau, MD, PhD ${ }^{4}$ Vuthy Ea, MS, ${ }^{1,2}$ Coline Coquart, ${ }^{5}$ Melissa Y. Frederic, $\mathrm{PhD},{ }^{1,2}$ 
Gael Gallouedec, MD, ${ }^{6}$ Jean-Paul Adenis, MD, ${ }^{7}$

Isabelle Benatru, $\mathrm{MD},{ }^{8}$ Michel Borg, $\mathrm{MD},{ }^{9}$ Pierre Burbaud, MD, PhD, ${ }^{10}$ Patrick Calvas, $\mathrm{MD}, \mathrm{PhD},{ }^{11}$ Laura Cif, MD, ${ }^{12}$ Philippe Damier, $\mathrm{MD}, \mathrm{PhD},{ }^{13}$ Alain Destee, $\mathrm{MD}, \mathrm{PhD},{ }^{14}$ Laurence Faivre, $\mathrm{MD}, \mathrm{PhD},{ }^{15}$ Lucie Guyant-Marechal, MD, ${ }^{16}$ Piotr Janik, MD, PhD, ${ }^{17}$ Samer Janoura, $\mathrm{MD},{ }^{18}$ Alexandre Kreisler, $\mathrm{MD}, \mathrm{PhD},{ }^{14}$, Anna Lusakowska, MD, PhD, ${ }^{17}$ Sylvie Odent, MD, PhD ${ }^{19}$ Anna Potulska-Chromik, MD, PhD, ${ }^{17}$

Monika Rudzińska, MD, PhD, ${ }^{20}$ Stephane Thobois, $\mathrm{MD}, \mathrm{PhD},{ }^{21}$ Isabelle Vuillaume, $\mathrm{MD}, \mathrm{PhD},{ }^{22}$ Christine Tranchant, $\mathrm{MD},{ }^{23}$ Sylvie Tuffery-Giraud, PhD, ${ }^{1,2}$ Philippe Coubes, MD, PhD, ${ }^{12}$ Bernard Sablonnière, $\mathrm{MD}, \mathrm{PhD},{ }^{22}$ Mireille Claustres, $\mathrm{MD}, \mathrm{PhD}, 1,2,5$, Gwenaelle Collod-Béroud, PhD, ${ }^{1,2}$ *

${ }^{1}$ INSERM, U827, Montpellier, France; ${ }^{2}$ Université Montpellier 1, UFR Médecine, Montpellier, France; ${ }^{3} \mathrm{CHU}$ Montpellier, Hôpital Gui de Chauliac, Service de Neuropédiatrie, Montpellier, France; ${ }^{4}$ Hôpitaux de Toulouse, Pôle Neurosciences, Toulouse, France;

${ }^{5} \mathrm{CHU}$ Montpellier, Hôpital Arnaud de Villeneuve, Laboratoire de Génétique Moléculaire,

Montpellier, France; ${ }^{6} \mathrm{CHU}$ Dupuytren, Service de Neurologie, Limoges, France; ${ }^{7} \mathrm{CHU}$ Dupuytren, Service d'Ophtalmologie, Limoges, France; ${ }^{8} \mathrm{CHU}$ de Dijon, Hôpital Général, Service de

Neurologie, Dijon, France; ${ }^{9} \mathrm{CHU}$ de Nice, Service de Neurologie, Nice, France; ${ }^{10} \mathrm{CHU}$ Pellegrin,

Service de Neurophysiologie, Clinique, Bordeaux,

France; ${ }^{11} \mathrm{CHU}$ Toulouse, Hôpital Purpan, Service de Génétique Médicale, Toulouse, France;

${ }^{12} \mathrm{CHU}$ Montpellier, Hôpital Gui de Chauliac,

Service de Neurochirurgie, Montpellier, France;

${ }^{13} \mathrm{CHU}$ Nantes, CIC0004, Service de Neurologie, Nantes, France ${ }^{14} \mathrm{CHU}$ de Lille, Service de

Neurologie, et Pathologie du Mouvement, Lille, France; ${ }^{15} \mathrm{CHU}$ de Dijon, Hôpital d'Enfants, Centre de Génétique, Dijon, France; ${ }^{16} \mathrm{CHU}$ de Rouen, Hôpital Charles Nicolle, Département de Neurologie, Rouen, France; ${ }^{17}$ Department of Neurology, Medical University of Warsaw, Poland; ${ }^{18}$ CHG Roanne, Service de Neurologie, Roanne, France; ${ }^{19}$ Service de Génétique Clinique, CHU de Rennes, Hôpital Sud, Rennes, France;

${ }^{20}$ Department of Neurology, Jagiellonian University Medical College, Poland;

${ }^{21}$ Hospices Civils de Lyon, Hôpital Neurologique, Service de Neurologie C, Lyon, France;

${ }^{22} \mathrm{CHRU}$ de Lille, Département de Biochimie, et de Biologie Moléculaire, Lille, France;

${ }^{23}$ Hôpitaux Universitaires de Strasbourg, Service de Neurologie, Strasbourg, France

\section{References}

1. Fuchs T, Gavarini S, Saunders-Pullman R, et al. Mutations in the THAP1 gene are responsible for DYT6 primary torsion dystonia. Nat Genet 2009;41:286-288.

2. Bressman SB, Raymond D, Fuchs T, Heiman GA, Ozelius LJ, Saunders-Pullman R. Mutations in THAP1 (DYT6) in early-onset dystonia: a genetic screening study. Lancet Neurol 2009;8: $441-446$.

3. Koukouni V, Martino D, Arabia G, Quinn NP, Bhatia KP. The entity of young onset primary cervical dystonia. Mov Disord 2007; 22:843-847.

4. Paisan-Ruiz C, Ruiz-Martinez J, Ruibal M, et al. Identification of a novel THAP1 mutation at R29 amino-acid residue in sporadic patients with early-onset dystonia. Mov Disord 2009;24. 2428-2429.

5. Bonetti M, Barzaghi C, Brancati F, et al. Mutation screening of the DYT6/THAP1 gene in Italy. Mov Disord 2009;24:2424-2427.

6. Djarmati A, Schneider SA, Lohmann K, et al. Mutations in THAP1 (DYT6) and generalised dystonia with prominent spasmodic dysphonia: a genetic screening study. Lancet Neurol 2009;8:447-452.

7. Houlden H, Schneider SA, Paudel R, et al. THAP1 mutations (DYT6) are an additional cause of early-onset dystonia. Neurology 2010;74:846-850.

8. Xiao J, Zhao Y, Bastian RW, et al. Novel THAP1 sequence variants in primary dystonia. Neurology 2010;74:229-238.

\section{Pantothenate Kinase-Associated Neurodegeneration: Clinical Description of 10 Patients and Identification of New Mutations}

Pantothenate kinase-associated neurodegeneration (PKAN) is a rare autosomal recessive neurodegenerative disorder of childhood onset, characterized by progressive dystonia and iron accumulation in the brain, mainly in the globus pallidus and the pars reticulata of the substantia nigra. ${ }^{1}$ Patients have mutations in the gene encoding pantothenate kinase 2 (PANK2), a key regulatory enzyme in the biosynthesis of coenzyme A. ${ }^{2}$

We ascertained 10 patients from 3 unrelated Algerian families between 1997 and 2008; all were examined at different stages of the disease and presented with early-onset, typical, ${ }^{3-5}$ and rarely described clinical PKAN features (Table 1 and Supplementary Fig. 1). Hyperactivity (Video) and attention deficit rarely described in previous series ${ }^{5}$ but observed in most of our patients were inaugural signs of the disease, as demonstrated by the absence of any other clinical signs in patient F2P4 at the age of 3 years. Pigmentary retinopathy, present in all our patients, was also considered as an early sign because it was already detectable in the neurologically asymptomatic patient (F2P4). The phenotype thereafter extended with abnormal falls

Additional Supporting Information may be found in the online version of this article.

*Correspondence to: Meriem Tazir, Department of Neurology, CHU Mustapha Bacha and Laboratoire de Neurosciences, Université d'Alger, Algérie, Algeria; meriem.tazir@sante.dz

Relevant conflicts of interest/financial disclosures: Nothing to report. This work received support from the Ministère de la Santé, de la Population et de la Réforme Hospitalière (Algeria), the Ministère de I'Enseignement Supérieur et de la Recherche Scientifique (Algeria), the Agence National de la Recherche (France, to A.D. and G.S.), the Association Française contre les Myopathies (AFM, France; to H.A.) and the Verum Foundation (Germany; to A.B.).

Full financial disclosures and author roles may be found in the online version of this article.

Published online 25 March 2011 in Wiley Online Library (wileyonlinelibrary.com). DOI: 10.1002/mds.23648 


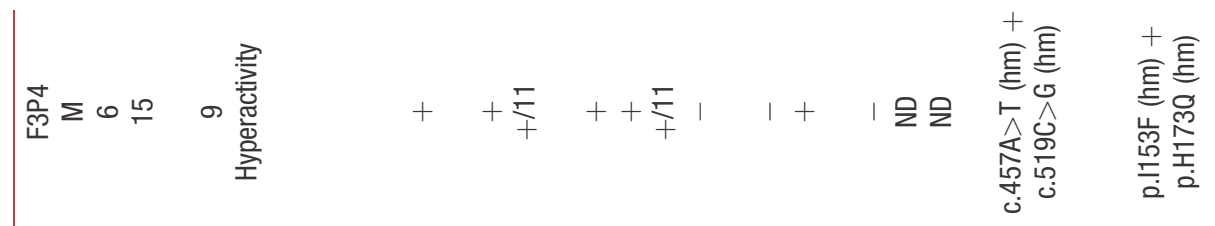

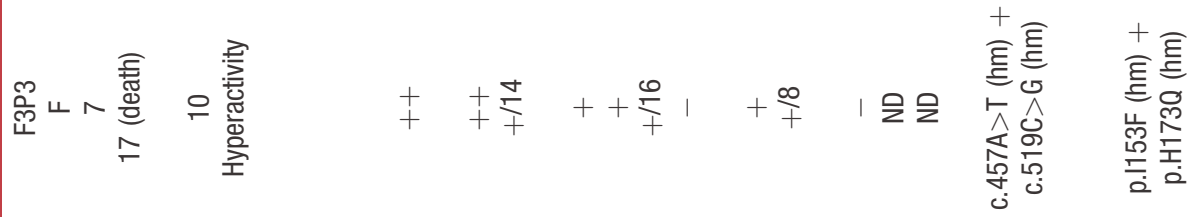

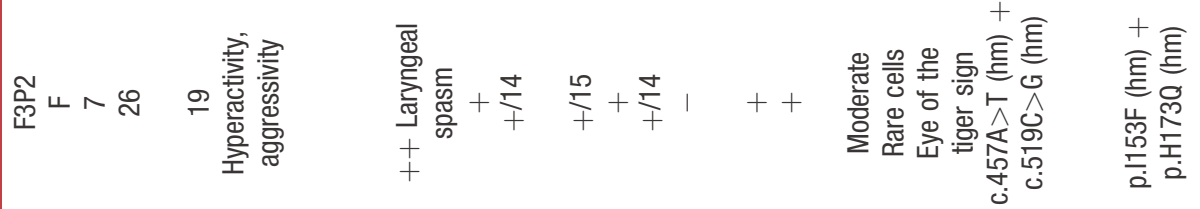

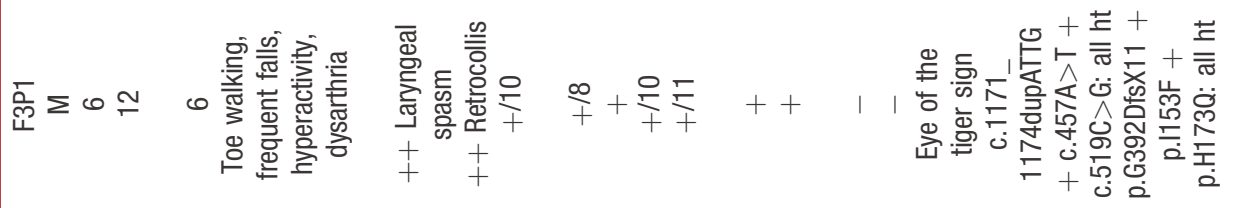

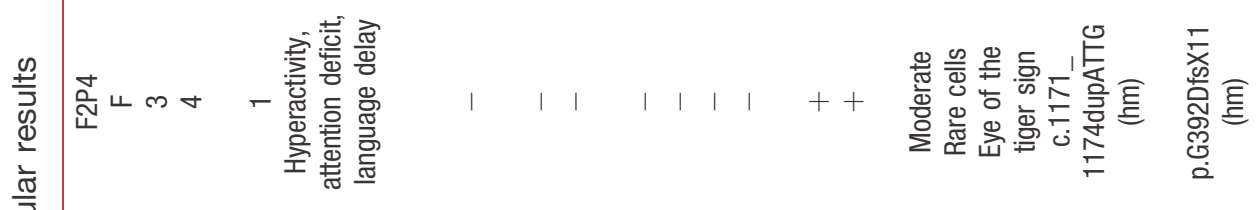

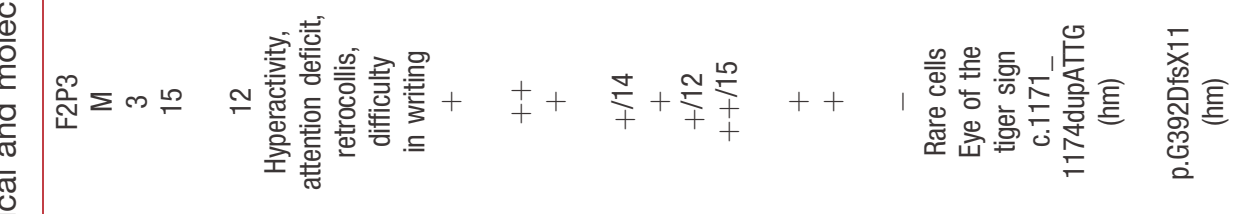

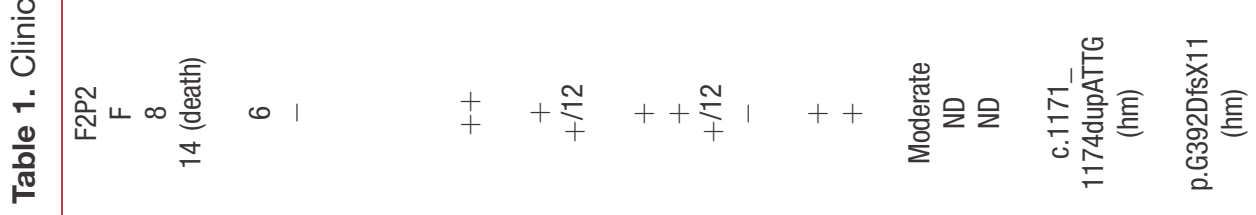

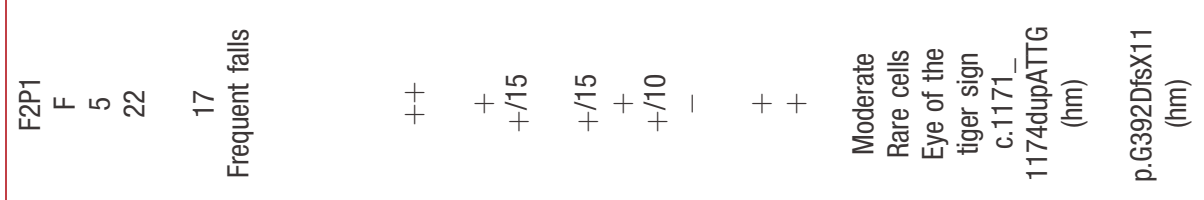

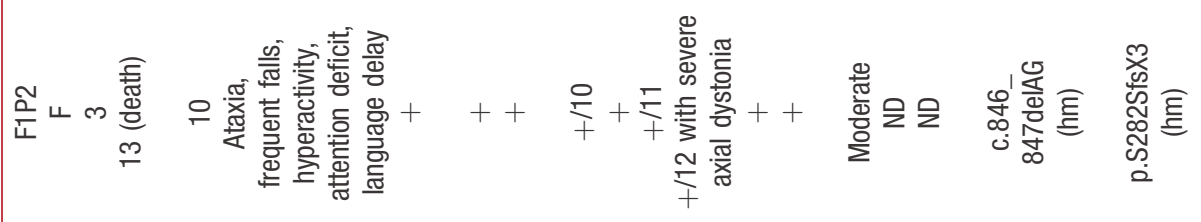

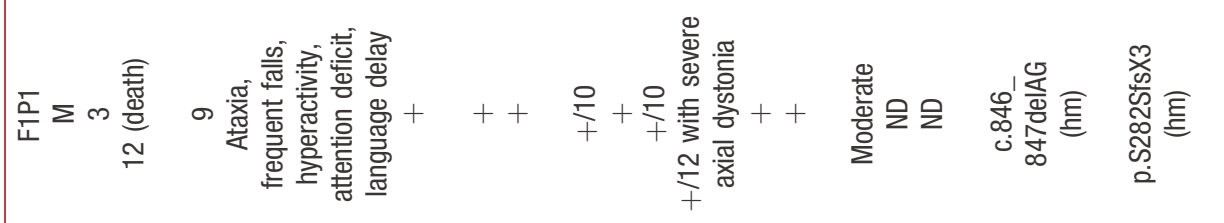

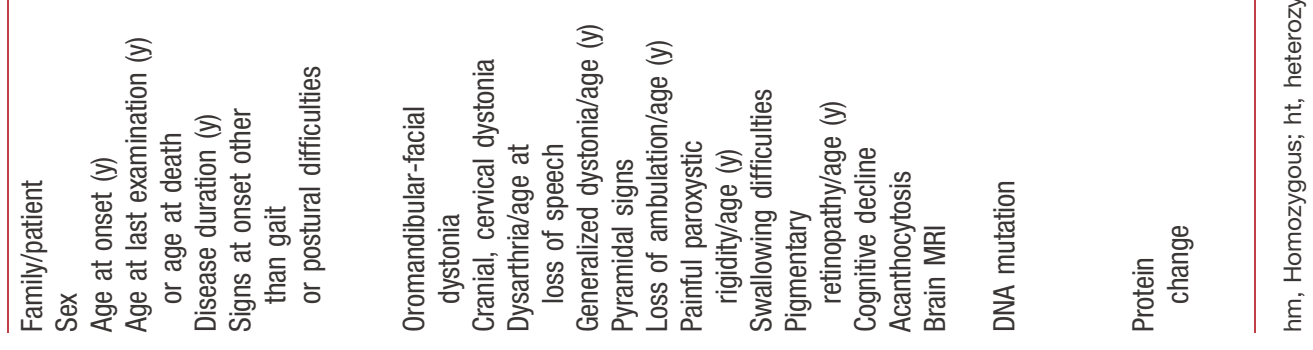


and gait or postural difficulties, followed by the typical PKAN signs (Video and Supplementary Fig. 2). Loss of speech was observed at a mean age of $9.5 \pm 1.4$ years. Progression was rapid in the first decade, with loss of independent ambulation at a mean age of $11.7 \pm 1.9$ years with generalized dystonia. Life expectancy differed greatly between patients, as some patients died during early adolescence, at 17 (F3P3) and 14 (F2P2), and others with the same mutation were still alive at 26 (F3P2) and 22 (F2P1).

The T2-weighted brain MRI showed the "eye of the tiger" sign, the specific pattern of hyperintensity within the hypointense medial globus pallidus. Interestingly, in the asymptomatic patient $\mathrm{F} 2 \mathrm{P} 4$, there was predominantly a hyperintensity within the globus pallidus (Supplementary Fig. 3).

Recently, 1 patient (F2P1) with oromandibular dystonia, difficulty with opening her jaw, and consequently a failure to thrive, was successfully treated with botulinum toxin, leading to better feeding.

Direct sequencing and MLPA analysis of PANK2 in 1 affected patient from each of the 3 families identified 2 known homozygous truncating PANK2 mutations (c.846_847delAG/ p.S282SfsX3 in exon 3 and c.1171_1174dupATTG/ p.G392DfsX11 in exon 5) that were shown to segregate with the disease in all patients in families 1 and 2, respectively. Interestingly, in 1 branch of family 3, all the patients were double homozygous for 2 missense variants (c.457A $>$ T/p.I153F and c.519C $>\mathrm{G} / \mathrm{p} . \mathrm{H} 173 \mathrm{Q}$ ) occurring in exon 2 . These variants were absent in 898 control chromosomes and were highly conserved in at least 10 species (Supplementary Fig. 1). It has been previously shown that truncating mutations are associated with an earlier age at onset compared with missense variants. ${ }^{3}$ In contrast, our 3 double homozygous patients with missense mutations had similar ages at onset as homozygous patients, with loss of function mutations, suggesting that both missense variants are deleterious, leading to a very low level of enzymatic activity. Interestingly, the single patient (F3P1) of the other branch of this family had a particular genotype that he inherited from his mother, the truncating mutation (c.1171_1174dupATTG/ p.G392DfsX1) identified in family 2, and received from his father, the 2 missense variants in cis position identified in the other branch of family 3. This is the first description of a triple compound heterozygous patient in PKAN, whereas this has been reported in other diseases. ${ }^{6,7}$ This triple compound heterozygote F3P1 was more severely affected than the other 3 members, suggesting a gradation in the deleterious effects according to the nature of the mutations. The c.1171_1174dupATTG mutation found in family 2 as well as in 1 branch of family 3 was associated with similar flanking haplotypes (Supplementary Fig. 1), suggesting a common ancestor.

In conclusion, we report 3 new PANK2 families (10 patients) and 2 novel missense mutations cosegregating in the $c$ is position in 1 kindred. Although the main typical signs of the disease associated with an early onset were present in all patients, as in previously reported cases, this report confirms the broad phenotypic spectrum of PKAN and differences in survival, even among siblings with identical mutations. Other genetic or epigenetic factors could play a role in this phenotypic heterogeneity.

Video Legend-Patient F2P3. Patient F2P3 presents with severe axial and upper limb dystonic movements with hyperextension of the neck and head together with painful laryngeal spasm and hypersalivation.

Video Legend-Patient F2P1. Patient F2P1 presents with axial and dystonic movements at all limbs with oromandibular dystonia.

Video Legend-Case F2P4. Case F2P4 has normal walk but instability on the half-turn.

Salima Assami, MD ${ }^{1}$ Hamid Azzedine, $\mathrm{PhD},{ }^{2,3}$ Sonia Nouioua, MD ${ }^{1}$ Emeline Mundwiller, $\mathrm{BS}^{2,3}$, Soulaiman Mahoui, MD, ${ }^{1}$ Samira Makri, MD, ${ }^{4}$ Meriam Djemai, MD, ${ }^{5}$ Djamel Grid, MD, ${ }^{6}$ Alexis Brice, MD, PhD, ${ }^{2,3,7}$ Tarik Hamadouche, $\mathrm{PhD},{ }^{8}$ Giovanni Stevanin, $\mathrm{PhD}$, 2,3,7,9 Meriem Tazir, $\mathrm{MD}^{1^{*}}$

${ }^{1}$ Department of Neurology, CHU Mustapha Bacha and Laboratoire de Neurosciences, Université d'Alger, Algérie, Algeria; ${ }^{2}$ INSERM, U975 (formerly U679), Paris, France; ${ }^{3}$ UPMC Univ. Paris 6 UMR_S975, CNRS 7225, Centre de Recherche de l'Institut du Cerveau et de la Moelle épinière, Hôpital Pitié-Salpêtrière, Paris, France; ${ }^{4}$ EHS Ali Ait Idir; ${ }^{5}$ Service de Neurologie, CHU Bab el Oned, Algiers, Algeria; ${ }^{6}$ Généthon, Paris, France; ${ }^{7}$ APHP, Department of Genetics, and Cytogenetics, Hôpital Pitié-Salpêtrière, Paris, France; ${ }^{8}$ Laboratoire de Biologie Moléculaire, Université Mhamed Bougara, Boumerdes, Algeria;

${ }^{9}$ Ecole Pratique des Hautes Etudes, Paris, France

\section{References}

1. Swaiman KF. Hallervorden-Spatz syndrome and brain iron metabolism. Arch Neurol. 1991;48:1285-1293.

2. Zhou B, Westaway SK, Levinson B, Johnson MA, Gitschier J, Hayflick SJ. A novel pantothenate kinase gene (PANK2) is defective in Hallervorden-Spatz syndrome. Nat Genet. 2001;28: 345-349.

3. Swaiman KF. Hallervorden-Spatz syndrome and brain iron metabolism. Arch Neurol. 1991;48:1285-1293.

4. Gregory A, Polster BJ, Hayflick SJ. Clinical and genetic delineation of neurodegeneration with brain iron accumulation. J Med Genet. 2009;46:73-80.

5. Pellecchia MT, Valente EM, Cif L, et al. The diverse phenotype and genotype of pantothenate kinase-associated neurodegeneration. Neurology. 2005;64:1810-1812.

6. Jayandharan G, Viswabandya A, Baidya S, et al. Six novel mutations including triple heterozygosity for Phe31Ser, 514delT and $516 \mathrm{~T} \rightarrow \mathrm{G}$ factor $\mathrm{X}$ gene mutations are responsible for congenital factor X deficiency in patients of Nepali and Indian origin. J Thromb Haemost. 2005;3:1482-1487.

7. Nurden AT, Breillat C, Jacquelin B, et al. Triple heterozygosity in the integrin alphaIIb subunit in a patient with Glanzmann's thrombasthenia. J Thromb Haemost. 2004;2:813-819. 


\section{Behavioral Factors Influence the Phenotype of Musician's Dystonia}

Focal dystonia in musicians (musician's dystonia, MD) is a task-specific movement disorder that presents with loss of voluntary motor control when a musician is playing the instrument. ${ }^{1,2}$ The pathophysiology is still not fully understood. $^{3}$ Recently, predilections of certain instruments to affect certain body parts were reported. ${ }^{4}$ Pianists and guitarists are affected predominantly in the right hand, bowed string players, in contrast, in the left hand. These predilections were shown to be related to the technical burden and spatiotemporal constraints required by the nature of the instrument. ${ }^{4,5}$ Two questions remain unanswered. First, may extrainstrumental workload, that is, intense usage of the dominant hand in daily-life activities, additionally affect the localization of MD? And, second, does predilection relate solely to the localization of dystonic movements, or does the nature of highly trained movements influence the type of dystonia? We hypothesized that (1) workload of daily activities given by handedness may additionally influence the localization of MD and (2) the nature of movements required by the respective instrument may additionally influence the dystonic movement patterns of MD. Focal, task-specific tremor (FT) is rare and sometimes the only symptom of MD. Although an increased ratio of patients with FT was seen among bowed string players, ${ }^{6}$ FT has not been reliably associated with specific movement patterns of certain instruments. According to our second hypothesis, we expected FT to be overrepresented in bowed string players because of the repetitive nature of similar movements in this group (vibrato movements in the left hand, repetitive bowing movements in the right hand) in contrast with all other instrument groups.

For the study, patients were recruited from the outpatient clinic of the Hanover Institute of Music Physiology and Musicians' Medicine. All patients diagnosed with MD from 1994 until 2007 were included $(\mathrm{n}=591)$. The following data were collected from patients' charts: (1) instrument played, (2) side of the affected hand/arm, and (3) selfdeclared handedness. None of the patients showed clinical evidence of essential tremor. To detect disproportionate handedness distributions in patients with unilateral hand dystonia (MHD; $\mathrm{n}=362$ ), we used a 1-way chi-square test contrasting the distribution of handedness in patients with right-sided MHD versus left-sided MHD. To analyze the dis-

*Correspondence to: Eckart Altenmüller, Institute of Music Physiology and Musicians' Medicine, University of Music and Drama, Hanover. Germany; eckart.altenmueller@hmtm-hannover.de

Relevant conflicts of interest/financial disclosures: Nothing to report. Full financial disclosures and author roles may be found in the online version of this article.

Published online 21 March 2011 in Wiley Online Library (wileyonlinelibrary.com). DOI: 10.1002/mds.23564 tribution of tremor versus nontremor dystonic symptoms in each of the 6 instrumental groups (keyboard, bowed string, plucked string, woodwind, brass, and percussion), we applied Fisher's exact tests. Each instrument group was contrasted with all other groups, resulting in one 2-by-2 table per instrument group. $P<.05$ (2-tailed) was considered statistically significant. For multiple Fisher's exact tests, Bonferroni correction was applied (corrected $\alpha=0.0083$ ).

Handedness distribution in patients with right- and leftsided MHD was significantly different $\left(\chi_{(1)}^{2}=4.07, P<\right.$ $.05)$ : The ratio of right-handers was higher in patients with right-sided MHD (92.4\%; left-handers, $7.6 \%)$ compared with those with left-sided MHD $(85.7 \%$; left-handers, $14.3 \%)$. Right-sided MHD was more frequent than leftsided in keyboard and plucked string players, with the converse pattern in bowed string players (each, $P<.05$; this will be reported elsewhere in detail). However, handedness was not associated with instrument groups (keyboard and plucked string players vs bowed string players, $\chi_{(1)}^{2}=0.03$, $P=.87)$. Among the 591 patients, $18(3.0 \%)$ suffered from FT, $571(96.6 \%)$ showed typical MD symptoms of cramping, and $2(0.3 \%$, excluded from the analysis $)$ had both symptoms. The ratio of patients with FT was higher in bowed string players compared with all other instrument groups $(9.9 \%$ vs $2.0 \%, P=.001)$. FT in bowed string players occurred only on the right side ( 2 patients had arm FT, 6 had hand FT). No significant differences were seen for the remaining instrument groups (each, $P>.018$ ).

Findings showed that, first, extrainstrumental burdens of daily-life activities reflected by handedness were related to localization of MHD. Moreover, second, the nature of movements required by the respective instrument was related to the dystonic movement patterns of $\mathrm{MD}$, as seen in the increased occurrence of FT in bowed string players. It has been discussed that both environmental and genetic factors are important in the development of focal dystonia. ${ }^{3,7}$ Genetic studies suggest that vulnerability to MD is subject to hereditary transmission. Based on previous epidemiological studies and our results, we suggest that phenotypic occurrence of MD is more heavily influenced by environmental and behavioral factors than previously assumed. As a limitation, it cannot be excluded that there are genetic factors that might determine both handedness and vulnerability to developing MHD in the dominant hand.

Acknowledgments: We thank Aurélie Hofmann for assistance with data acquisition.

Volker Baur, MSc, ${ }^{1,2}$ Hans-Christian Jabusch, MD ${ }^{3}$ Eckart Altenmüller, $\mathrm{MD}^{1, " *}$

${ }^{1}$ Institute of Music Physiology and Musicians' Medicine, University of Music and Drama, Hanover, Germany; ${ }^{2}$ Division Neuropsychology, Institute of Psychology, University of Zurich, Zurich, Switzerland; ' Institute of Musicians' Medicine, University of Music Carl Maria von Weber, Dresden, Germany 


\section{References}

1. Altenmüller E. Focal dystonia: advances in brain imaging and understanding of fine motor control in musicians. Hand Clin. 2003; 19:523-538.

2. Jankovic J, Ashoori A. Movement disorders in musicians. Mov Disord. 2008;23:1957-1965.

3. Lin PT, Hallett M. The pathophysiology of focal hand dystonia. J Hand Ther. 2009;22:109-113; quiz 114.

4. Conti AM, Pullman S, Frucht SJ. The hand that has forgotten its cunning-lessons from musicians' hand dystonia. Mov Disord. 2008;23:1398-1406.

5. Jabusch HC, Altenmüller E. Focal dystonia in musicians: from phenomenology to therapy. Adv Cogn Psychol. 2006;2:207-220.

6. Lederman RJ. Tremor in instrumentalists: influence of tremor type on performance. Med Probl Perform Art. 2007;22:70-73.

7. Schmidt A, Jabusch HC, Altenmüller E, et al. Etiology of musician's dystonia: familial or environmental? Neurology. 2009;72:1248-1254.

\section{Racial Differences May Influence the Role of Cholecystokinin Polymorphisms in Parkinson's Disease Hallucinations}

Psychosis is a frequently troublesome complication in Parkinson's disease (PD). ${ }^{1}$ Various genetic polymorphisms affecting dopamine have been reported as risk factors for PD-related complications such as dyskinesias and hallucinations. ${ }^{2,3}$ Cholecystokinin (CCK) has been implicated in psychiatric disorders including schizophrenia and panic disorder, and CCK and receptor (CCKAR and CCKBR) gene polymorphisms have been investigated in PD hallucinations. ${ }^{4-6}$ CCK-dopamine interactions may contribute to the neurobiology of psychiatric disorders, as CCK colocalizes with dopamine in mesolimbic neurons, including those in the nucleus accumbens and amygdala, and modulates dopaminergic release. In Asian PD patients, an increased hallucination risk was associated with CCK and CCKAR gene polymorphisms. $^{4,5}$ Because genetic polymorphisms vary across racial groups, we aimed to replicate these findings in white PD patients with chronic hallucinations compared with those who never hallucinated.

We conducted a case-control study at the Rush University Movement Disorders clinic, examining 88 pairs of white PD patients with and without chronic hallucinations, matched for

Additional Supporting Information may be found in the online version of this article.

*Correspondence to: Jennifer G. Goldman, Department of Neurological Sciences, Rush University Medical Center, Chicago, Illinois, USA; Jennifer_G_Goldman@rush.edu

Relevant conflicts of interest/financial disclosures: This study was supported by the Parkinson's Disease Foundation, New York, New York. Drs. Goldman and Goetz have received research support from the Parkinson's Disease Foundation. Dr. Berry-Kravis has consulted and had clinical trial funding from Novartis, Roche, Seaside Therapeutics and Neuropharm LTD for projects unrelated to Parkinson's Disease or hallucinations. Full financial disclosures and author roles may be found in the online version of this article.

Published online 19 April 2011 in Wiley Online Library (wileyonlinelibrary.com). DOI: 10.1002/mds.23655
Table 1. CCK and CCK receptor genotype and allelic frequencies

Hallucinators, n (\%) Nonhallucinators, n (\%)

$P$ value

Genotype frequencies

$\begin{array}{lcc}\text { CCK }-45 \mathrm{C} / \mathrm{T} & & \\ \mathrm{CC} & 61(69.3) & 67(76.1) \\ \text { CT } & 26(29.5) & 18(20.5) \\ \text { TT } & 1(1.13) & 3(3.4) \\ \text { CCKAR 779T/C } & & \\ \text { CC } & 2(2.3) & 2(2.3) \\ \text { CT } & 24(27.3) & 23(26.1) \\ \text { Tा } & 62(70.5) & 63(71.6) \\ \text { CCKBR 1550G/A } & & \\ \text { AA } & 0(0) & 0(0) \\ \text { AG } & 12(13.6) & 12(13.6) \\ \text { GG } & 75(86.2) & 75(86.2) \\ \end{array}$

\begin{tabular}{|c|c|c|c|c|c|}
\hline \multicolumn{4}{|c|}{ Allelic frequencies } & \multicolumn{2}{|c|}{$P$ value } \\
\hline & $\begin{array}{c}\text { Hallucinators, } \\
\mathrm{n}(\%)\end{array}$ & $\begin{array}{c}\text { Nonhallucinators, } \\
\mathrm{n}(\%)\end{array}$ & $\begin{array}{l}\text { Total, } \\
\text { n (\%) }\end{array}$ & $\begin{array}{c}\text { Allele } \\
\text { frequency }\end{array}$ & $\begin{array}{l}\text { No. of } \\
\text { alleles }\end{array}$ \\
\hline \multicolumn{6}{|c|}{ CCK $-45 \mathrm{C} / \mathrm{T}$} \\
\hline C & 148 (84) & $152(86)$ & $300(85)$ & .55 & .55 \\
\hline $\mathrm{T}$ & $28(16)$ & $24(14)$ & $52(15)$ & & \\
\hline \multicolumn{6}{|c|}{ CCKAR } \\
\hline \multicolumn{6}{|c|}{ 779T/C } \\
\hline C & $28(16)$ & 27 (15) & $55(16)$ & .88 & .88 \\
\hline $\mathrm{T}$ & 148 (84) & $149(85)$ & $297(84)$ & & \\
\hline \multicolumn{6}{|c|}{ CCKBR } \\
\hline 15 & & & & & \\
\hline$A$ & $12(7)$ & $12(7)$ & $24(7)$ & 1.0 & 1.0 \\
\hline $\mathrm{G}$ & $160(93)$ & $160(93)$ & $320(93)$ & & \\
\hline
\end{tabular}

age within 3 years, disease duration within 5 years, and dopaminergic medications (levodopa, agonist, or both). Cases had hallucinated at least 3 times weekly for the past 2 months and had not experienced hallucinations before dopaminergic treatment, whereas controls had never hallucinated. Only controls with at least 1 year of continual clinical follow-up were included. Mini-Mental State Examination (MMSE), Unified Parkinson Disease Rating Scale (UPDRS) motor section, and Hoehn and Yahr staging were also administered. Only white, non-Hispanic, non-Latino patients participated. The Rush University Institutional Review Board approved this research.

Genomic DNA from coded samples was analyzed for CCK -45C/T, CCKAR 779T/C, and CCKBR 1550G/A polymorphisms by polymerase chain reaction. ${ }^{6}$ We specifically examined polymorphisms identified in the Asian studies, including the promoter region $C C K-45 \mathrm{C} / \mathrm{T}$ polymorphism, which may influence $C C K$ gene transcription based on its Sp1 cis-binding element location. Based on prior studies, our sample size of 88 pairs afforded $>90 \%$ power to detect a difference of $22 \%$ between cases and controls, assuming a CCK-T allele frequency of $14 \%$ in white PD controls. ${ }^{4-7}$ Genotypic and allelic frequencies were compared using Mantel-Haenszel and chi-square tests. Combined CCK-T and CCKAR-C alleles were analyzed by Mantel-Haenszel tests for synergistically increased hallucinatory risk.

There were no significant differences between PD hallucinators and nonhallucinators in age, sex, disease duration, or levodopa equivalent doses (Supplemental Material). PD hallucinators had worse MMSE scores and motor function. 
Mean clinical follow-up for nonhallucinating controls was 3.79 years (SD, 3.22 years), maximum 15 years.

$C C K, C C K A R$, and $C C K B R$ genotype frequencies were in Hardy-Weinberg equilibrium. For CCK, CCKAR, and $C C K B R$, there were no significant differences in genotype distributions or allele frequencies between hallucinators or nonhallucinators (Table 1). In fact, the CCK-T allele was modestly represented in both groups $(16 \%$, hallucinators; $14 \%$, nonhallucinators; $p=.55)$. We also did not detect increased hallucinatory risk with combined CCK-T and CCKAR-C alleles.

Our matched case-control study did not replicate the association between CCK or CCKAR polymorphisms and increased hallucination risk previously found in Japanese and Chinese PD patients. In both Asian studies, the CCK-T allele frequency in PD hallucinators was about 40\%, a finding detected in smaller hallucinator samples $(n=23$ and $n=45$, respectively). ${ }^{4,5}$ In contrast, the overall CCK-T allele frequency was $15 \%$ in our white PD cohort, without significant differences between hallucinators and nonhallucinators. Our CCK-T allele frequency, however, was similar to studies in American white populations (14\%), but lower than frequencies reported in Asian populations (32\%, Japanese; 33\%, Chinese). ${ }^{7}$ Our study was powered to detect a contribution of the CCK-T allele to hallucination status that would account for a similar magnitude of risk, as proposed in the Asian studies, despite the lower population CCK-T allele frequency in whites. Thus, the CCK-related polymorphisms studied appear to differentially affect hallucination risk in PD across different racial groups. Genetic polymorphisms as risk factors for disease-related complications such as hallucinations should be interpreted within the context of racial and ethnic diversity.

Our methodological strengths include a well-matched study population, diagnoses by movement disorder specialists, and follow-up of nonhallucinating patients to ensure group classification. Limitations include the tertiary-care referral pattern, study of only gene polymorphisms showing prior associations, and that even with rigorous follow-up of nonhallucinators, we cannot confirm that they will never hallucinate.

Although particular CCK and CCK receptor gene polymorphisms may increase hallucination risk in Asian PD patients, the lack of differences in allele frequencies in our cohort suggests that these polymorphisms are not substantial contributors to the psychosis risk in white PD patients.

Jennifer G. Goldman, MD, MS, ${ }^{1 *}$

Darcy Marr, MS, ${ }^{2}$ Lili Zhou, MD, ${ }^{3}$

Bichun Ouyang, $\mathrm{PhD},{ }^{1}$ Sue E. Leurgans, PhD, ${ }^{1,4}$

Elizabeth Berry-Kravis, MD, PhD, ${ }^{1,3,5}$ and Christopher G. Goetz, $\mathrm{MD}^{1}$

\footnotetext{
${ }^{1}$ Department of Neurological Sciences, Rush University Medical Center, Chicago, Illinois, USA;

${ }^{2}$ University of British Columbia, Vancouver, British Columbia, Canada;

${ }^{3}$ Department of Pediatrics, Rush University

Medical Center, Chicago, Illinois, USA;

${ }^{4}$ Department of Preventive Medicine, Rush

University Medical Center, Chicago, Illinois, USA; and ${ }^{5}$ Department of Biochemistry, Rush

University Medical Center, Chicago, Illinois, USA
}

\section{References}

1. Fenelon G, Alves G. Epidemiology of psychosis in Parkinson's disease. J Neurol Sci. 2010;289:12-17.

2. Kaiser R, Hofer A, Grapengiesser A, et al. L-dopa-induced adverse effects in PD and dopamine transporter gene polymorphism. Neurology. 2003;60:1750-1755.

3. Goetz CG, Burke PF, Leurgans S, et al. Genetic variation analysis in parkinson disease patients with and without hallucinations: case-control study. Arch Neurol. 2001;58:209-213.

4. Fujii C, Harada S, Ohkoshi N, et al. Association between polymorphism of the cholecystokinin gene and idiopathic Parkinson's disease. Clin Genet. 1999;56:394-399.

5. Wang J, Si YM, Liu ZL, Yu L. Cholecystokinin, cholecystokinin-A receptor and cholecystokinin-B receptor gene polymorphisms in Parkinson's disease. Pharmacogenetics. 2003;13:365-369.

6. Goldman JG, Goetz CG, Berry-Kravis E, Leurgans S, Zhou L. Genetic polymorphisms in Parkinson disease subjects with and without hallucinations: an analysis of the cholecystokinin system. Arch Neurol. 2004;61:1280-1284.

7. Harada S, Okubo T, Tsutsumi M, Takase S, Muramatsu T. A new genetic variant in the $\mathrm{Sp} 1$ binding cis-element of cholecystokinin gene promoter region and relationship to alcoholism.Alcohol Clin Exp Res. 1998;22(Suppl 3):93S-96S.

\section{“Silly Walks” in Parkinson's Disease: Unusual Presentation of Dopaminergic-Induced Dyskinesias}

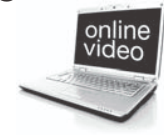

It is widely recognized that dopaminergic-induced dyskinesias can interfere with gait in advanced Parkinson's disease (PD). ${ }^{1}$ However, levodopa-induced dyskinesias can sometimes take bizarre forms and may easily be mistaken for psychogenic movement disorders. Here, we present 4 PD patients with strikingly similar bizarre gaits related to the effects of levodopa.

Patient 1 developed clumsiness of the left leg and hand at age 44 . He was diagnosed with PD, and levodopa treatment was initiated. Six years later, a psychogenic cause was suspected because of bizarre leg movements interfering with stability and gait. We discovered that these dyskinesias mainly occurred at the beginning and end of each levodopa dose effect (Video Patient 1, Segments 1 and 2). In-between these

Additional Supporting Information may be found in the online version of this article.

*Correspondence to: Evžen Rủžička Department of Neurology and Centre of Clinical Neuroscience, First Faculty of Medicine and General University Hospital, Charles University in Prague, Prague, Czech Republic; eruzi@|f1.cuni.cz

Relevant conflicts of interest/financial disclosures: Professor Evžen Růžička and Kateřina Zárubová are supported by the Czech Ministry of Education, research grant MSM0021620849 and Czech Ministry of Health, grants NS 10336-and NT 11331. Professor John G. Nutt is supported by Veterans Administration PADRECC, NIH/NIA AG006457, and NIH/NINDS. Professor Bastiaan R Bloem is supported by the Prinses Beatrix fonds and by a research grant of The Netherlands Organisation for Health Research and Development (VIDI research grant 016.076.352).

Full financial disclosures and author roles may be found in the online version of this article.

Published online 14 April 2011 in Wiley Online Library (wileyonlinelibrary.com). DOI: 10.1002/mds.23667 
periods, the patient experienced motor improvement (Video Patient 1, Segment 3).

Patient 2 developed hypokinesia and rigidity in the left arm at age 38. Levodopa was initiated, with good effect on motor function. Three years later, he complained of a short and unpredictable effect of levodopa, usually with a period of immobility and abnormal leg movements preceding the advent of the next dose effect (Video Patient 2, Segment 1). After overnight withdrawal of all medication, the patient showed generalized bradykinesia plus dystonia of the right foot (Video Patient 2, Segment 2). Thirty-five minutes after a levodopa dose, ballistic kicking and stamping appeared in the left leg on walking, along with persistent dystonic posturing of the left arm (Video Patient 2, Segment 3). In his full "on" state, the patient showed only mild choreodystonia not interfering with gait (Video Patient 2, Segment 4).

Patient 3 was diagnosed with PD beginning in his left arm at age 35 . He started levodopa at age 36 with a good response. At age 41 he developed motor fluctuations and dyskinesias. During the "on" phase, he exhibited a striking, stereotyped kicking gait (Video Patient 3, Segment 1). When "off," he was slow, with marked difficulty walking (Video Patient 3, Segment 2). Bilateral deep brain stimulation of the subthalamic nucleus (DBS STN) improved his parkinsonism and allowed reduction of his medications. He no longer exhibits this gait pattern.

Patient 4 developed PD at the age of 39 . He responded well to dopaminergic medication, but after 4 years he developed wearing-off and dopaminergic-induced dyskinesias. In his best "on" phase, the patient shows violent choreatic dyskinesias involving the trunk, arms, and legs (Video Patient 4, Segment 1). In the practically defined "off" state, the patient's gait is clearly bradykinetic, with small, slow, and shuffling steps (Video Patient 4, Segment 2). The patient subsequently received bilateral DBS STN, with substantial improvement of dyskinesias and gait.

There are several common elements to these case presentations. The first is the bizarre yet fairly stereotyped gait patterns. When videos of these patients were presented at conferences to experienced movement disorder specialists, the gait was generally thought to be psychogenic and reminiscent of the gaits shown in Monty Python's classic TV sketch "The Ministry of Silly Walks" (http://www.youtube. com/watch?v=9Z1BUglE6Hc). The gait we present here indeed looks bizarre, but it is also remarkably stereotyped across patients seen in 4 movement disorders clinics. Recurring characteristics include the stepping with kicks, high knee elevations, and ballistic "stamping" of 1 lower limb, generally on the side first affected by PD. In addition, dystonic postures of the contralateral foot and ipsilateral arm were seen in 2 patients, and dancing movements with hops and pelvis rotations were seen in 1 case.

An additional shared feature is that all are male patients whose PD began before the age of 45 . In keeping with known experiences with such young-onset patients, ${ }^{2}$ they all developed early motor fluctuations and dyskinesias, starting only several years after the initiation of dopaminergic treatment.

Another important element was the timing of these abnormal movements in relation to the intake and clinical efficacy of dopaminergic medication. The first 2 patients clearly had a diphasic pattern: dyskinesias developed shortly following a levodopa dose, at the beginning of the therapeutic effect. When the levodopa effect increased further to reach a full "on" state, the dyskinesias largely disappeared, and gait improved considerably, consistent with previous descriptions of biphasic levodopa-induced dyskinesias that mainly affect subjects with early-onset PD and that are characterized by a stereotypic pattern, with a dystonic or ballistic form, and a violent expression. ${ }^{2-4}$ The predominance in the most affected leg corresponds to the observation that dyskinesias start and predominate in the leg contralateral to where dopaminergic denervation in the dorsal putamen is greatest. ${ }^{5}$ Optimizing dopaminergic therapy or DBS can be helpful in these patients, as was also demonstrated here.

Most importantly, the bizarre gait pattern should not be misdiagnosed as a psychogenic movement disorder, even if voluntary movements are sometimes superimposed as a compensation for the dyskinesias interfering with gait (possibly in patient 4). Another possibility is embellishment that, although not widely recognized, may occur as a superimposed movement abnormality in patients with otherwise genuine PD. ${ }^{6}$ Showing a similar case (\#17), Hayes et $\mathrm{al}^{7}$ appropriately warned about the danger of labeling a bizarre gait as psychogenic just on the basis that it is unlike anything that has been seen before.

\section{Legends to the Video}

Video Patient 1, Segment 1. When first seen by us, the patient presented with ballistic leg movements occurring at the beginning and at the end of each levodopa dose effect.

Video Patient 1, Segment 2. Twenty-five minutes after the levodopa dose, prominent rhythmic elevations of the left lower limb developed, interfering with walking and persisting when standing.

Video Patient 1, Segment 3. In the "on" state 1 hour after the levodopa dose, the patient showed only moderate choreodystonic movements not interfering with balance and gait.

Video Patient 2, Segment 1. On the first visit, ballistic stamping of the left leg markedly interfered with the patient's gait.

Video Patient 2, Segment 2. After an overnight withdrawal of all dopaminergic medication, a generalized bradykinesia and dystonic arching of the right sole is seen.

Video Patient 2, Segment 3. Thirty-five minutes after levodopa/carbidopa 100/25 mg, involuntary movements appear on the lower limbs, with left leg kicking on walking, soon followed by ballistic leg stamping, along with persistent dystonic posturing of the patient's left arm.

Video Patient 2, Segment 4. Fifty minutes after the levodopa dose, the patient is in the "on" state, with mild choreodystonia not markedly interfering with gait.

Video Patient 3, Segment 1. Striking, stereotyped kicking gait in the "on" state.

Video Patient 3, Segment 2. When "off” levodopa, the patient is slow and has marked difficulty walking.

Video Patient 4, Segment 1. In the patient's best "on" phase, about 1 hour after intake of $187.5 \mathrm{mg}$ of levodopa and $8 \mathrm{mg}$ of ropinirole, his walking is severely hampered by violent choreatic dyskinesias involving the trunk, arms, and legs. 
Video Patient 4, Segment 2. In the "off" state, more than 12 hours after intake of the last dose of medication, the patient's gait is clearly hypokinetic, with small, slow, and shuffling steps.

Evžen Růžička, MD, DSc, ${ }^{1 *}$ Kateřina Zárubová, $\mathrm{MD},{ }^{2}$ John G. Nutt, MD, ${ }^{3}$ and Bastiaan R. Bloem, MD, $\mathrm{PhD}^{4}$

${ }^{1}$ Department of Neurology and Centre of Clinical Neuroscience, First Faculty of Medicine and General University Hospital, Charles University in Prague, Prague, Czech Republic; ${ }^{2}$ Department of Neurology, Second Faculty of Medicine and University Hospital Motol, Charles University in Prague, Prague, Czech Republic; ${ }^{3}$ Department of Neurology, Oregon Health o Science University, Portland, Oregon, USA; and ${ }^{4}$ Department of Neurology and Parkinson Centre Nijmegen, Donders Institute for Brain, Cognition and Behaviour, Radboud University Nijmegen Medical Centre, Nijmegen, The Netherlands

\section{References}

1. Bloem BR, Bhatia KP. Gait and balance in basal ganglia disorders. In: Bronstein AM, Brandt T, Nutt JG, Woollacott MH, eds. Clinical Disorders of Balance, Posture and Gait. London, UK: Arnold; 2004:173-206.

2. Quinn N, Critchley P, Marsden CD. Young onset Parkinson's disease. Mov Disord. 1987;2:73-91.

3. Lhermitte F, Agid Y, Signoret JL. Onset and end-of-dose levodopainduced dyskinesias. Possible treatment by increasing the daily doses of levodopa. Arch Neurol. 1978;35:261-263.

4. Marconi R, Lefebvre-Caparros D, Bonnet AM, Vidailhet M, Dubois B, Agid Y. Levodopa-induced dyskinesias in Parkinson's disease phenomenology and pathophysiology. Mov Disord. 1994;9:2-12.

5. Vidailhet M, Bonnet AM, Marconi R, Gouider-Khouja N, Agid Y. Do parkinsonian symptoms and levodopa-induced dyskinesias start in the foot? Neurology. 1994;44:1613-1616.

6. Benaderette S, Zanotti Fregonara P, Apartis E, et al. Psychogenic parkinsonism: a combination of clinical, electrophysiological, and [(123)I]-FP-CIT SPECT scan explorations improves diagnostic accuracy. Mov Disord. 2006;21:310-317.

7. Hayes MW, Graham S, Heldorf P, de Moore G, Morris JG. A video review of the diagnosis of psychogenic gait: appendix and commentary. Mov Disord. 1999;14:914-921.

\section{Immediate Versus Delayed Electrical Stimulation Boosts Botulinum Toxin Effect: A Pilot Study}

Electrical stimulation (ES) is reported to enhance the effect of botulinum toxin type A (BTX-A), but there is disagreement on the best ES protocol (time of administration, rate, duration). ${ }^{1-5}$ We carried out a pilot study aimed at comparing the efficacy of a single ES session of the injected muscles immediately after BTX-A administration versus repeated ES sessions beginning the day after inoculation.

Patients were recruited in the Neurorehabilitation Unit of the University Hospital of Verona, Italy. Inclusion criteria were first unilateral stroke, between 6 and 18 months after stroke, flexed elbow with spasticity of biceps brachii (BB) graded at least 2 (range, 0-5) on the Modified Ashworth Scale (MAS), and last BTX-A injection or any rehabilitative treatment at least 6 months prior to recruitment. Exclusion criteria were fixed contractures or bony deformities of the affected arm, previous treatment of arm spasticity with neurolytic or surgical procedures, and other neurological or orthopedic conditions involving the affected arm. Concentric needle electromyography was used to rule out patients with active denervation. Patients gave their consent for participation in the study, which was approved by the local Ethics Committee.

BTX-A (Botox; Allergan, Irvine, CA) 100 IU diluted with $2 \mathrm{~mL}$ of saline $0.9 \%$ was injected into the $\mathrm{BB}$ and the abductor digiti minimi (ADM) muscles of the affected arm. $\mathrm{ADM}$ was chosen because it offers a simple neurophysiological marker of neuromuscular blockade and would have caused a very small disadvantage in the case of complete blockade. The BTX-A dose was $80 \mathrm{U}$ for the BB and $15 \mathrm{U}$ for the ADM in each patient. After injection, patients were randomized into 2 groups. All patients received ES of the injected muscles (rectangular current pulses, $4 \mathrm{~Hz}, 0.2 \mathrm{~ms}$, intensity adjusted to elicit visible muscle contraction). Group A received ES of the injected muscles for 60 minutes immediately after BTX-A administration. Group B received ES for 30 minutes a day for 3 consecutive days, beginning the day after injection. None of the patients underwent any other treatment for spasticity during the study period.

All patients were evaluated immediately before (T0) and 4 weeks after (T1) BTX-A injection by the same examiner, who was blinded to the ES procedure they had received. Outcome measures were BB spasticity measured with the MAS and ADM compound muscle action potential (CMAP) amplitude. A decreased CMAP amplitude is considered a valid neurophysiologic quantification of toxin-induced neuromuscular blockade. ${ }^{2}$

The CMAP was recorded from the ADM muscle by supramaximal ulnar nerve stimulation at the wrist using disposable $\mathrm{Ag} / \mathrm{AgCl}$ surface electrodes with belly-tendon montage. An infrared lamp was used to maintain hand skin temperature $>31^{\circ} \mathrm{C}$ during the recording. The position of the electrodes at T0 was recorded, and the electrodes were put in the same position at $\mathrm{T} 1$.

Differences between groups in the outcome measures were evaluated with the Mann-Whitney test, whereas differences between single variables in each group were evaluated with the Wilcoxon test at T1 versus T0. The significance level was $P<.05$.

Twenty-four patients ( 15 men; mean age, 63.7 years; 18 ischemic/6 hemorrhagic stroke; 15 right/9 left hemiplegia) were recruited from among 47 subjects with spastic

\footnotetext{
*Correspondence to: Nicola Smania, Neuromotor and Cognitive Rehabilitation Research Center, Department of Neurological, Neuropsychological, Morphological and Movement Sciences, University of Verona, Italy; nicola.smania@univr.it
}

Relevant conflicts of interest/financial disclosures: Nothing to report. Full financial disclosures and author roles may be found in the online version of this article.

Published online 29 April 2011 in Wiley Online Library (wileyonlinelibrary.com). DOI: 10.1002/mds.23678 
Table 1. Outcome measures before and 4 weeks after injection

\begin{tabular}{|c|c|c|c|c|c|c|}
\hline \multirow[b]{2}{*}{ Outcome measures } & \multirow[b]{2}{*}{ Group } & \multirow[b]{2}{*}{$\begin{array}{l}\text { T0 Mean } \\
\text { (SD) }\end{array}$} & \multirow[b]{2}{*}{$\begin{array}{l}\text { T1 Mean } \\
\quad(\mathrm{SD})\end{array}$} & \multirow{2}{*}{$\frac{\begin{array}{c}\text { Within-group comparison } \\
\text { (Wilcoxon signed ranks test) }\end{array}}{\text { T0 }-\mathrm{T} 1, P \text { value }(Z)}$} & \multicolumn{2}{|c|}{$\begin{array}{l}\text { Between-groups comparison } \\
\text { (Mann-Whitney } U \text { test) }\end{array}$} \\
\hline & & & & & T0, $P$ value $(Z)$ & T1, $P$ value $(Z)$ \\
\hline \multirow[t]{2}{*}{ MAS at the elbow $(0-5)$} & Group A & $2.58(0.90)$ & $1.25(0.97)$ & $0.001(-3.176)^{\mathrm{a}}$ & $0.890(-0.139)$ & $0.015(-2.439)^{\mathrm{a}}$ \\
\hline & Group B & $2.50(0.80)$ & $1.67(0.94)$ & $0.002(-3.162)^{\mathrm{a}}$ & & \\
\hline \multirow{2}{*}{$\begin{array}{l}\text { ADM muscle CMAP } \\
\text { amplitude }(\mathrm{mV})\end{array}$} & Group A & $11.60(4.00)$ & $4.36(2.77)$ & $0.002(-3.061)^{\mathrm{a}}$ & $0.862(-0.173)$ & $0.040(-2.051)^{\mathrm{a}}$ \\
\hline & Group B & $12.41(4.15)$ & 7.24 (3.87) & $0.002(-3.061)^{\mathrm{a}}$ & & \\
\hline
\end{tabular}

SD, standard deviation; MAS, Modified Ashworth Scale; CMAP, compound muscle action potential; ADM, abductor digiti minimi muscle.

aSignificant comparison $(P<.05)$.

hemiparesis consecutively evaluated from March 2009 to January 2010. None of the patients showed evidence of active denervation. No significant difference was found between the 2 groups in the clinical variables at baseline. Group A showed significantly lower MAS scores and better CMAP reductions than group B at T1 (Table 1).

BTX-A is rapidly internalized by high-affinity receptormediated endocytosis, which mainly occurs in a few minutes, and its translocation process occurs between 15 and 40 minutes after toxin exposure. ${ }^{6}$ Our results support greater chemodenervation, consistent with increased internalization of the toxin when ES is performed during the uptake process. Limitations of this study are the small sample size and the absence of a group treated only with BTX-A.

Previous findings about the effectiveness of long-term delayed ES protocols in enhancing BTX-A effect may be explained as follows: (1) several authors did not clearly state the time between injection and ES, and probably some of them started ES early after inoculation ${ }^{4,5}$; (2) some ES protocols stimulated also antagonist muscles ${ }^{1,3}$ probably involving other mechanisms (see reciprocal inhibition); and (3) ES may reduce spasticity by itself. ${ }^{7}$

Acknowledgments: We thank Prof. Cesare Montecucco for his helpful suggestions and Patrizia Ianes for her technical assistance in preparation of the manuscript.

Alessandro Picelli, MD, ${ }^{1,2}$ Nicola Smania, MD, ${ }^{1 *}$ Ilaria Storti, MD ${ }^{3}$ Daniele Munari, PT, ${ }^{1}$ Carla Fontana, MD, ${ }^{3}$ Antonio Fiaschi, MD, ${ }^{3}$ Valter Santilli, $\mathrm{MD},{ }^{2,4}$ and Stefano Tamburin, $\mathrm{MD}, \mathrm{PhD}^{3}$

${ }^{1}$ Neuromotor and Cognitive Rehabilitation Research Center, Department of Neurological Neuropsychological, Morphological and
Movement Sciences, University of Verona Verona, Italy; ${ }^{2} \mathrm{PhD}$ course in Experimental Physical Medicine and Rehabilitation applied to Human Locomotor System, University of Rome "La Sapienza", Rome, Italy; ${ }^{3}$ Department of Neurological, Neuropsychological Morphological and Movement Sciences Neurology Section, University of Verona Verona, Italy; and ${ }^{4}$ Department of Physical Medicine and Rehabilitation, University of Rome "La Sapienza", Rome, Italy

\section{References}

1. Hesse S, Jahnke MT, Luecke D, Mauritz KH. Short-term electrical stimulation enhances the effectiveness of Botulinum toxin in the treatment of lower limb spasticity in hemiparetic patients. Neurosci Lett 1995;201:37-40.

2. Eleopra R, Tugnoli V, De Grandis D. The variability in the clinical effect induced by botulinum toxin type A: the role of muscle activity in humans. Mov Disord 1997;12:89-94.

3. Hesse S, Reiter F, Konrad M, Jahnke MT. Botulinum toxin type A and short-term electrical stimulation in the treatment of upper limb flexor spasticity after stroke: a randomized, double-blind, placebo-controlled trial. Clin Rehabil 1998;12:381-388.

4. Detrembleur C, Lejeune TM, Renders A, Van Den Bergh PY. Botulinum toxin and short-term electrical stimulation in the treatment of equinus in cerebral palsy. Mov Disord 2002;17:162-169.

5. Frasson E, Priori A, Ruzzante B, Didonè G, Bertolasi L. Nerve stimulation boosts botulinum toxin action in spasticity. Mov Disord 2005;20:624-629.

6. Grumelli C, Verderio C, Pozzi D, Rossetto O, Montecucco C, Matteoli M. Internalization and mechanism of action of clostridial toxins in neurons. Neurotoxicology 2005;26:761-767.

7. Smania N, Picelli A, Munari D, et al. Rehabilitation procedures in the management of spasticity. Eur J Phys Rehabil Med 2010;46: $423-438$. 